\title{
THE “MERE-REMINDER” EFFECT OF SALIENT CALORIE LABELING
}

\author{
INDRANIL GOSWAMI
}

OLEG URMINSKY*

*Indranil Goswami (igoswami@ chicagobooth.edu) is a doctoral candidate in Marketing, phone: 773-531-5130, and Oleg Urminsky (oleg.urminsky@chicagobooth.edu) is Associate Professor of Marketing and Charles M. Harper Faculty Fellow at the Booth School of Business, University of Chicago, 5807 S. Woodlawn Ave., Chicago, IL 60637, phone: 773-834-4710. Both authors contributed equally to this research.

We thank the Initiative on Global Markets at the University of Chicago Booth School for grant funding. The authors thank Joel Huber, Ran Kivetz, Anastasiya Pocheptsova, Abby Sussman and David Tannenbaum for useful feedback. 


\begin{abstract}
Calorie labeling, an increasingly common policy intervention, has had mixed effects on consumer food choices. We show that visual salience of the calorie labels, rather than merely information content or format, is the key to reducing calorie. Our findings indicate that effective labeling, more visually salient than standard industry disclosures, works primarily as a reminder, by prompting people to consider nutrition rather than by providing new information. Both visually salient information and completely non-informative "mere reminders" to consider calories have similar effects on calorie choices, by making people more likely to incorporate their beliefs about nutrition into their decision. As a consequence, when consumers perceive high-calorie items as healthy, calorie labeling working as mere reminders will be less effective and can even backfire, leading to more choices of healthy-seeming high-calorie food options. The findings underscore the need for experimentally testing the psychological consequences of even ostensibly informational interventions.
\end{abstract}


Historically, high levels of obesity (Flegal et al. 2012) have had serious consequences for cardiovascular health and mortality (Kramer et al. 2013), accounting for approximately $20 \%$ of national medical spending ( Cawley and Meyerhoefer, 2013). Since obesity is primarily caused by overconsumption of calories (Bray et al. 2012; Swinburn and Ravussin 2009; Cutler et al. 2003), reducing the calories people choose to consume is a critical policy objective. However, there has been a remarkable lack of consensus on which interventions are effective at reducing calorie choices.

Psychological research on food choices has focused on the fundamental conflict between hedonic short-term impulses and self-control cognitions involving goals and long-term consequences (Ainslie 1975; Hoch and Loewenstein, 1991; Hoffmann et al. 2009). Whether or not a person over-consumes is influenced by identification of self-control conflicts (Bartels and Urminsky, 2015; Myrseth and Fishbach, 2009) as well as by contextual influences on selfcontrol (Ruderman 1986), such as decision timing (Milkman et al. 2010), menu design (Parker and Lehmann, 2014) and convenience (Rozin et al. 2011). Based on this literature, people will choose fewer calories when their own cognitions and the decision context facilitate self-control.

In contrast, policy interventions in the U.S. have proceeded from the premise that obesity is largely driven by a lack of accurate information (Black 2014), leading to a focus on calorie and nutritional labeling. Beginning with New York City's 2008 fast food menu-labeling law, both voluntary and required labeling initiatives have proliferated. Most recently, the FDA has issued new guidelines requiring restaurant menus, vending machines, and packaged goods to provide "clear and conspicuous" calorie information and specifying minimal font size and color requirements (Federal Register, 2014). These informational interventions are also easier to 
justify as a legitimate exercise of government regulatory authority, compared with other interventions, such as size restrictions or extra taxes on unhealthy foods.

However, this reliance on labeling raises the question of whether such interventions are effective at reducing calorie consumption. A comprehensive review of lab and field studies has found inconsistent results for the effect of calorie labels on reducing calorie choices (Long et al. 2015). Although, on average, menu calorie labeling yielded a significant 18.1 calorie per meal reduction, in-restaurant studies with a control group only demonstrated a statistically nonsignificant 7.6 calorie reduction, and the effect of calorie labeling varied widely across studies. Recent research has suggested that these weak effects of labeling may be due to people's difficulty in interpreting calories (an abstract unit) and effective labeling interventions may therefore need to provide an intuitive basis of comparison, such as equivalent exercise time (Bleich et al. 2013; Dowray et al. 2013).

In this paper we provide a novel account of when and how information disclosures are more likely to affect calorie choices. We propose that the reason calorie labeling interventions are ineffective has little to do with interpretability of the information and that the answer instead lies in the effects of visual salience on decision making. We show that calorie labeling, when sufficiently visually salient, shifts choices, regardless of whether the information is framed in terms of calories or equivalent exercise. Visual salience is crucial, not only for information to be noticed, but primarily because it facilitates actively deliberating about cues (Shen and Urminsky, 2013) and incorporating cues into decisions (Weber and Kirsner, 1997). We propose that visually salient information affects choices primarily via a reminder effect, prompting people to consider nutrition rather than merely providing new information. As a result, we find that even non-informative "mere-reminders" yields similar results as salient new information. 
The mere-reminder effect also predicts that providing visually salient labeling can reduce the calories chosen, even without materially changing beliefs, by simply prompting people to select foods they already believe to be relatively healthier than other options. This has important implications on the effect of salient disclosures on calorie choices. Even when people misestimate absolute calories in foods (Chandon and Wansink, 2007), their sense of relative calorie levels is often reasonably well-calibrated (Burton et al. 2006; Tang et al. 2014). Therefore, in those cases when the seemingly healthy options are actually higher in calories, even visually salient labeling will not be effective in reducing calories taken.

We conducted three studies, two of which used real food choices, with over 2,000 adult consumers to test the relative efficacy of labeling interventions, as well as two key predictions of our account. In our studies, we compare two kinds of interventions - salient information and noninformative mere reminders. Both types of interventions were tested in two ways, one framed in terms of calories and the other in terms of calorie-equivalent minutes of exercise. These interventions are compared to two control conditions, one with no information and another which provides calorie information in a realistic low-salience format reflecting current industry practices.

\section{STUDY 1: SALIENT LABELS AND MERE REMINDERS BOTH REDUCE CALORIE CHOICES}

\section{Method.}

Study 1 used a framed field experiment (Harrison and List, 2004) where museum visitors chose among candy bars from boxes displaying the information manipulations on the box lids in exchange for completing a brief survey (see Figure 1). We tested the effect of both objective information and mere-reminders on real food choices. We had access to the museum for three 
days, and collected all participants we could during that time. This yielded 838 participants, of which two were eliminated because their choice of candy bar was not observed.

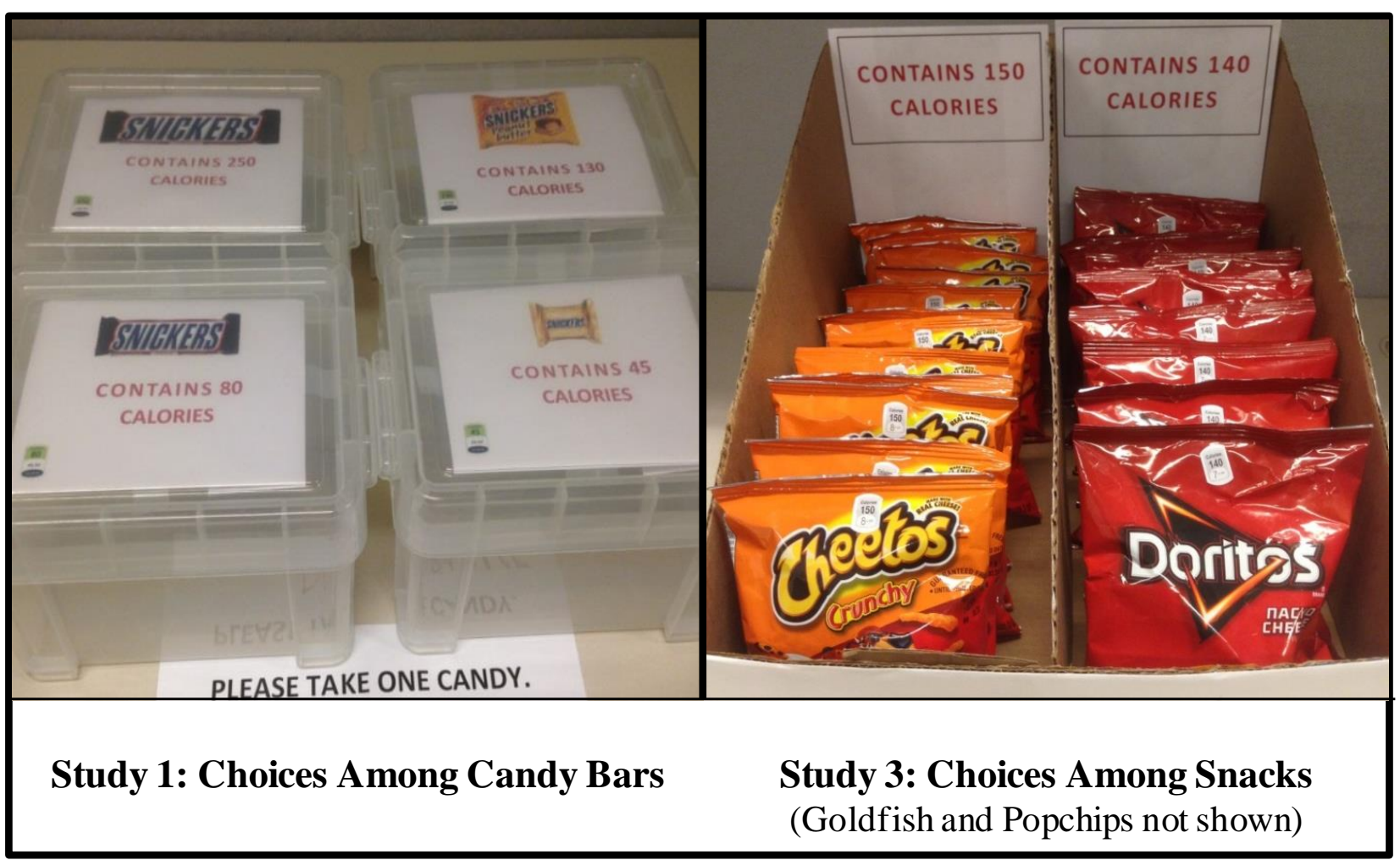

Figure 1: Sample informational interventions, including oval-shaped industry format icons (green in Study 1, white stickers in Study 3) as well as salient calorie information, in large red font on the boxes.

The study employed a 3 (survey mere-reminders) x 4 (box lid information) full-factorial between-subjects design. The three different surveys contained the mere-reminder manipulations (analogous to a mere-measurement intervention, Levav and Fitzsimmons 2006) or a control version. In each survey, participants were asked to estimate seven quantities, three of which were food-related questions. In the calorie mere-reminder condition, participants estimated the calories in three foods unrelated to the subsequent choice (McDonald's Big Mac, half-cup of vanilla ice cream, Starbucks blueberry muffin). In the exercise-equivalent merereminder condition, participants estimated how much time exercising it would take to burn the 
calories in the same three foods. In the control (no reminder) version of the survey, participants were asked to estimate quantities unrelated to nutrition for the same three foods.

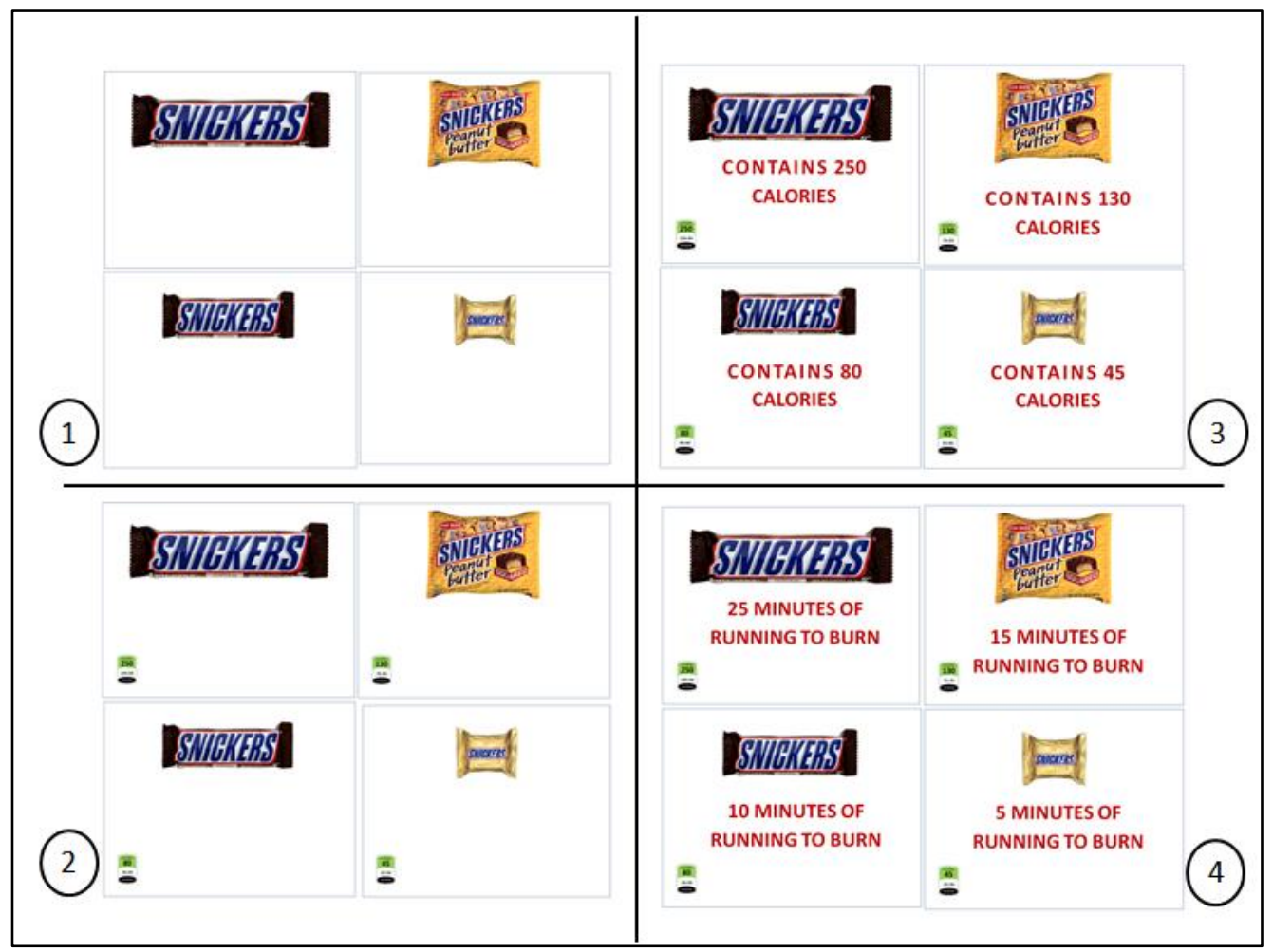

Figure 2: Four different versions of the box lids (1=Control, $2=$ Disclosure using industry format, $3=$ Salient Calorie disclosure, 4=Salient Exercise Equivalent disclosure) used in Study 1

After completing the brief survey, participants chose among four differently sized Snickers candy bars (ranging from 45 to 250 calories) as a reward. Participants selected from among four boxes, each displaying the name and picture of the candy bar inside (Figure 2). The box-lid labels were changed every 30 minutes, rotating among four versions: control, industryformat information, salient calorie information or salient exercise-equivalent information. The no-information control labels only displayed names and pictures. In the industry-format control condition, the labels also featured a small (3/4") industry-format icon used at the time (similar to the "Clear on Calories" front-of-package voluntary labeling initiative), which displayed the 
calories and percent of daily recommended allowance. In the salient-information conditions, the labels also displayed either calories or the equivalent minutes of running time in 38-point red Calibri font, in addition to the industry-format icon.

\begin{tabular}{|l|l|c|c|c|}
\hline & & & \multicolumn{2}{|c|}{ Calories taken } \\
Box lid information & Reminder survey version & $N$ & Mean & SD \\
\hline Mere Names & Control & 55 & 158.2 & 101.4 \\
\hline Industry-format icon & Control & 69 & 182.7 & 87.0 \\
\hline Merged Control & $\mathbf{1 2 4}$ & $\mathbf{1 7 1 . 8}$ & $\mathbf{9 4 . 1}$ \\
\hline Salient Calorie & 74 & 144.9 & 103.1 \\
\hline Salient Exercise Equivalent (EE) & Control & 76 & 143.8 & 89.9 \\
\hline Merged Salient Information Only & Control & $\mathbf{1 5 0}$ & $\mathbf{1 4 4 . 3}$ & $\mathbf{9 6 . 3}$ \\
\hline Mere Names & Calorie mere-reminder & 55 & 163.4 & 99.1 \\
\hline Mere Names & EE mere-reminder & 59 & 138.1 & 91.0 \\
\hline Industry-format icon & Calorie mere-reminder & 67 & 163.4 & 99.6 \\
\hline Industry-format icon & EE mere-reminder & 69 & 146.4 & 103.4 \\
\hline Merged Mere-Reminder Only & & $\mathbf{2 5 0}$ & $\mathbf{1 5 2 . 7}$ & $\mathbf{9 8 . 6}$ \\
\hline Salient Calorie & Calorie mere-reminder & 78 & 134.0 & 105.1 \\
\hline Salient Calorie & EE mere-reminder & 76 & 119.8 & 100.7 \\
\hline Salient Exercise Equivalent (EE) & Calorie mere-reminder & 79 & 136.7 & 93.0 \\
\hline Salient Exercise Equivalent (EE) & EE mere-reminder & 79 & 141.7 & 95.8 \\
\hline Merged Salient Information With Mere-Reminder & $\mathbf{3 1 2}$ & $\mathbf{1 3 3 . 2}$ & $\mathbf{9 8 . 6}$ \\
\hline \multicolumn{2}{|l|}{ Any Intervention (Salient Information or Reminder) } & $\mathbf{7 1 2}$ & $\mathbf{1 4 2 . 4}$ & $\mathbf{9 8 . 4}$ \\
\hline
\end{tabular}

Table 1: Average calories chosen in each experimental cell in Study 1, as well as merged conditions (control, salient information only, mere-reminder only and both interventions).

Results.

There was no difference in calories chosen between the two control conditions.

Displaying the accurately-sized industry-format icons did not reduce the average calories chosen, compared to the no-information control $(\mathrm{M}=182.7$ vs. $158.2, t(122)=1.45, p=.151, d=.26)$. The two control conditions were therefore combined as a single baseline for subsequent analysis. We also found no main effect of framing. There was no difference between calorie and exerciseequivalent information on the box lids, averaging across the different survey versions, $(\mathrm{M}=$ 132.8 vs. $140.7, \mathrm{t}(460)=.87, \mathrm{p}=.387, d=.08)$. Likewise, there was no difference between calorie and exercise equivalent reminders in the survey, averaging across the different box lids $(\mathrm{M}=$ 
147.6 vs. $136.2, \mathrm{t}(560)=1.37, \mathrm{p}=.172, d=.12)$. We collapsed the framing versions for subsequent analysis, yielding four means of interest: control, mere-reminder only, salient information only and salient information with mere-reminder (Table 1).

First, we compare the simple means of the calories chosen in the experimental conditions (Figure 3). Calories chosen were lower in the salient-information-only conditions, compared to the control conditions $(\mathrm{M}=144.3$ vs. $171.8, t(272)=2.38, p=.018, d=.29)$. Calories chosen were also directionally lower in the mere-reminder-only conditions, compared to the control conditions ( $\mathrm{M}=152.7$ vs. $171.8, t(372)=1.79, p=.074, d=.20)$. Thus, the non-informative mere-reminder yielded a reduction in calories chosen that was approximately two-thirds of the reduction from providing salient information. However, the difference in calories chosen between the salient-information-only and mere-reminder-only conditions was not significant ( $\mathrm{M}$ $=144.3$ vs. $152.7, t(398)=.83, p=.408, d=.09)$.

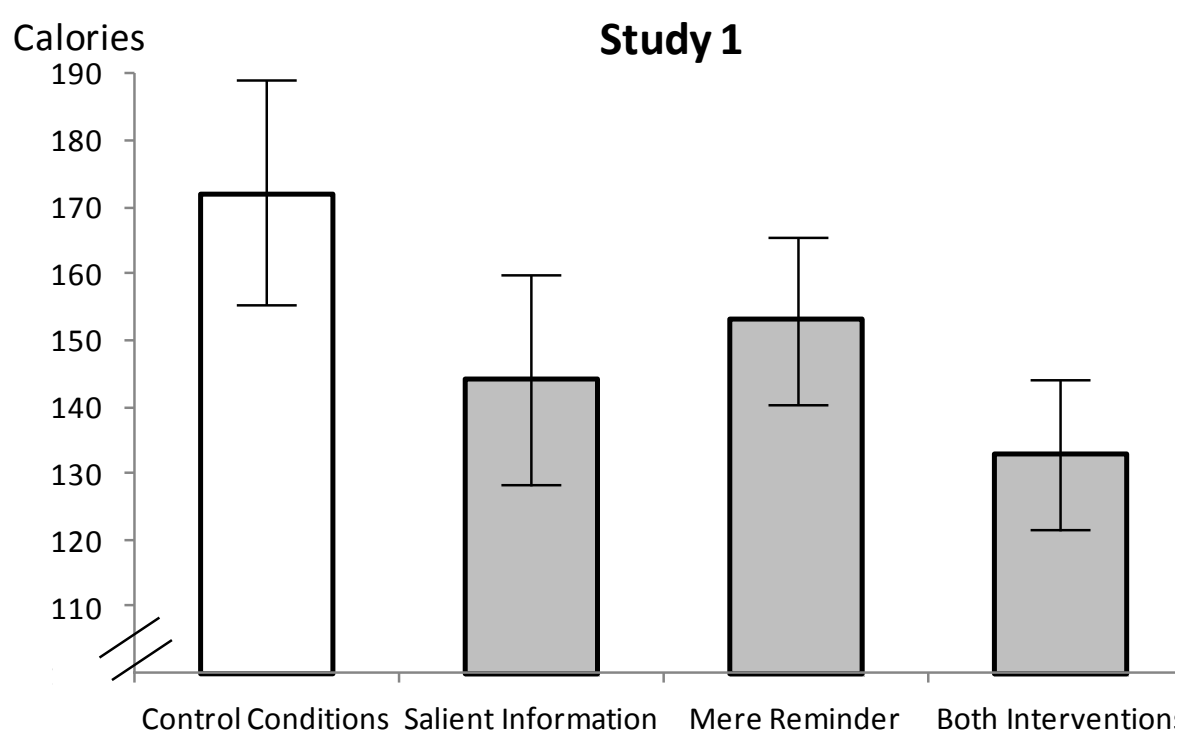

Figure 3: Average calories taken in Study 1. The vertical lines are 95\% CIs. 
A regression analysis revealed similar results (see Appendix VII, Table S1.2). Any salient intervention (i.e. salient information disclosure or non-informative mere-reminders) significantly reduced calories taken $\left(\beta_{\text {SALIENT }}=-23.29, \mathrm{SE}=10.11, p=.021\right)$, but there was no significant difference between the reduction in calories chosen from salient information disclosure alone versus non-informative mere-reminders alone $\left(\beta_{\text {COMPARISON }}=4.18, \mathrm{SE}=5.03\right.$, $p=.406)$.

\section{Discussion.}

In Study 1, adult decision makers made real choices between snacks, having been exposed to informational interventions, or to mere-reminders to think about nutrition, or both. Both salient informational disclosure and uninformative mere-reminders reduced calories chosen (compared to the non-salient information disclosure in the control condition) to a similar extent. This suggests that salient disclosures are effective in reducing calories taken, even when nonsalient disclosures with the same informational content have no effect. In fact, the effect of salient disclosures appears to not be attributable to providing people with the information they are missing for decision making. Instead, the salient disclosure reminded people to think about calories, an objective than can also be achieved by non-informative mere-reminders.

Some prior researchers have proposed that the mixed results of calories disclosure interventions may be due to people's lack of understanding calories (Bleich et al. 2012) and therefore translating numeric calorie information to a more intuitive metric (e.g., exercise cost) might be more effective (Sunstein 2015). However, our results find no evidence for this suggestion. We do not find any significant reduction in calories chosen when using a salient 
exercise-equivalent disclosure compared to salient calorie-only disclosure, as would be predicted by the lack-of-comprehension account.

From a policy point of view, it is also important to confirm that interventions to reduce calorie choices are effective specifically for people who are overweight. Overweight participants $(\mathrm{BMI}>25)$ chose an average of 181.1 calories in the control conditions, in the absence of salient disclosures or mere-reminders. Consistent with the overall results, overweight participants chose significantly fewer calories when prompted, by either salient-information or mere-reminders, to consider calories $(\mathrm{M}=136.3$ vs. $181.1, t(362)=3.41, p=.001, d=.46)$. Directionally smaller differences were observed for non-overweight participants, $(\mathrm{M}=144.6$ vs. 161.0, $t(374)=1.06, p$ $=.291, d=.17$ ), but intervention effectiveness did not significantly depend on BMI $(F(1,736)=1.96, p=.163)$. The findings were also consistent across other participant demographics, including gender, age, income, number of years of schooling and ethnicity.

In the Study 1 museum setting, as in many food-choice contexts, both distraction (Mann and Ward, 2007) and social interaction (Herman and Polivy, 2005) could have affected the results. Furthermore, Study 1 represented an unplanned food choice occasion and it is possible that decision makers think about such situations different from a planned food choice occasion (e.g., getting lunch). In the next study, participants instead chose in private a sandwich for lunch from one of eight versions of a hypothetical restaurant menu containing pictures, names and ingredients.

\section{STUDY 2: THE EFFECT OF MERE-REMINDERS FOR PRIVATE CHOICES}

\section{Method:}


We attempted to recruit approximately 600 online participants (100 per cell). Of the 616 complete surveys, records with duplicate IP addresses and participants who failed an attention check were excluded prior to data analysis. The remaining valid participants $(\mathrm{N}=545)$ had been randomly-assigned to one of six conditions and shown accurate pictures, names and primary ingredients for six McDonalds chicken sandwiches (presented as unbranded), ranging from 350 to 670 calories (Figure 4). A pre-test and second study using similar materials are reported in Supplementary Appendix II.

The study included two control conditions (no information and non-salient industry standard information), salient information conditions and mere-reminder conditions. In the noinformation control condition, no additional information was provided. In the industry-format control condition, participants were shown calorie information, displayed in the same font-size (10-point) as the ingredients, per FDA regulations, and the same color. In the two salientinformation conditions, participants were shown either calorie information or minutes of running needed to burn the equivalent number of calories, in bold 14-point font with an explanation in red, or both. Lastly, in two separate mere-reminder conditions, participants were shown the control condition information, and were asked to estimate the number of either calories or equivalent minutes of running for each sandwich. In all conditions, participants then made a hypothetical sandwich choice. 


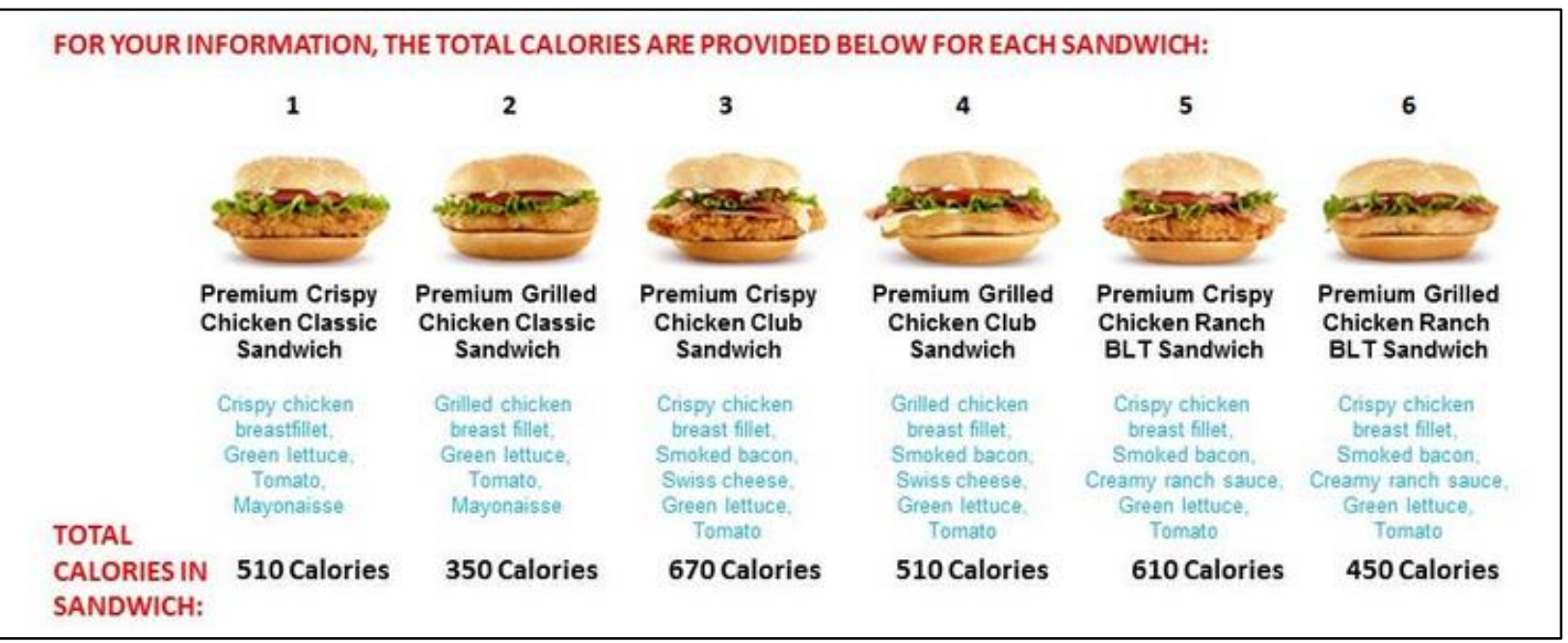

Figure 4: Stimuli from the Salient Calorie Disclosure Condition in Study 2

Results.

Displaying the industry-format calorie information (i.e. same size and font as the menu information) did significantly reduce the average calories chosen, compared to the noinformation control $(\mathrm{M}=511.7$ vs. $547.3, t(268)=2.60, p=.010, d=.32)$. For the sake of consistency, we combined the control conditions as a single baseline for subsequent analysis. However, as reported in the supporting information, the results are very similar if we instead use the industry-format calorie information as the sole control condition.

As in Study 1, we found no main effect of framing. There was no difference between either calorie and exercise equivalent information $(\mathrm{M}=487.9$ vs. $479.8, t(93)=.37, p=.715, d=$ $.08)$, or between calorie and exercise equivalent mere-reminders $(\mathrm{M}=494.2$ vs. 502.0, $t(135)=$ $.40, p=.693, d=.07)$. We collapsed the framing versions for subsequent analysis, yielding three means of interest: control, mere-reminder only and salient information only (see Table 2). 


\begin{tabular}{|l|c|c|c|}
\hline & & \multicolumn{3}{|c|}{ Calories taken } \\
Menu information & $N$ & Mean & SD \\
\hline Mere Names & 131 & 547.3 & 105.2 \\
\hline Non-Salient Calorie & 139 & 511.7 & 118.1 \\
\hline Merged Control & $\mathbf{2 7 0}$ & $\mathbf{5 2 9 . 0}$ & $\mathbf{1 1 3 . 2}$ \\
\hline Salient Calorie & 48 & 487.9 & 101.6 \\
\hline Salient Exercise Equivalent (EE) & 47 & 479.8 & 114.7 \\
\hline Merged Salient Information Only & $\mathbf{9 5}$ & $\mathbf{4 8 3 . 9}$ & $\mathbf{1 0 7 . 8}$ \\
\hline Calorie Mere-Reminder & 67 & 494.2 & 112.0 \\
\hline EE Mere-Reminder & 70 & 502.0 & 119.3 \\
\hline Merged Mere-Reminder Only & $\mathbf{1 3 7}$ & $\mathbf{4 9 8 . 2}$ & $\mathbf{1 1 5 . 4}$ \\
\hline Both Salient Calorie \& EE & $\mathbf{4 3}$ & $\mathbf{4 7 0 . 0}$ & $\mathbf{1 1 2 . 4}$ \\
\hline Any Intervention (Salient Information or Reminder) & $\mathbf{2 7 5}$ & $\mathbf{4 8 8 . 8}$ & $\mathbf{1 1 2 . 4}$ \\
\hline
\end{tabular}

Table 2: Average calories chosen in each experimental cell in Study 2, as well as merged conditions (control, salient information only and mere-reminder only).

Compared to the control conditions, calories chosen were lower in the salientinformation-only conditions $(\mathrm{M}=479.6$ vs. $529.0, t(406)=4.22, p<.001, d=.44)$ and in the mere-reminder-only conditions $(\mathrm{M}=498.2$ vs. $529.0, t(405)=2.58, p=.010, d=.27$; see Figure 5). Once again, the non-informative mere-reminder yielded a reduction in calories chosen that was approximately two-thirds of the reduction from providing salient information. However, the difference in calories chosen between the salient-information-only and mere-reminder-only conditions was not significant ( $\mathrm{M}=483.9$ vs. $498.2, t(230)=0.95, p=.34, d=.13)$.

A regression analysis revealed similar results (see Appendix VII, Table S2.2). Any salient intervention (i.e. salient information disclosure or non-informative mere-reminders) significantly reduced calories taken $\left(\beta_{\text {SALIENT }}=-37.93, \mathrm{SE}=10.19, p<.001\right)$, but there was no significant difference between the reduction in calories chosen from salient information disclosure alone versus non-informative mere-reminders alone $\left(\beta_{\text {COMPARISON }}=7.14, \mathrm{SE}=7.53\right.$, $p=.343)$. 


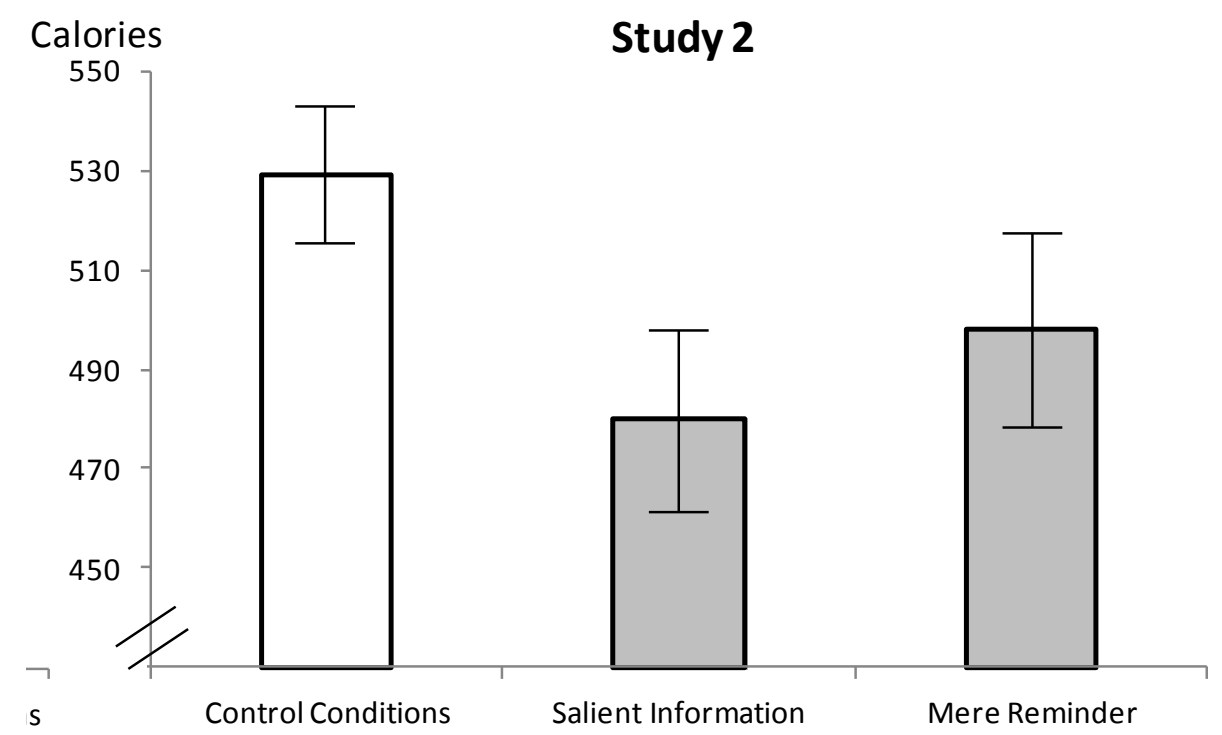

Figure 5: Average calories taken in Study 1 and Study 2. The vertical lines are 95\% CIs.

\section{Discussion.}

In Study 2, we replicated the findings of Study 1 in a setting where participants made a planned food-choice that was relatively free from distraction or influence by others. This was important since it was possible that the salience of the information disclosure is only important when people are distracted from paying full attention. This possibility was partially supported by the finding that non-salient calorie disclosure was significantly more effective in influencing calorie choices than no information at all in the low-distraction decision environment of Study 2. However, salience still mattered, and the salient information-only disclosures were more effective than the non-salient calorie disclosure $(\mathrm{M}=479.6$ vs. $511.7, t(275)=2.35, p=.02)$. Moreover, we did not find any statistical difference between the calories chosen with salient disclosures and uninformative mere reminders, consistent with our proposed mere reminder account.

As in Study 1, we confirmed that salient disclosures and mere-reminders were effective for overweight participants, prompting them to choose significantly fewer calories than in the control conditions $(\mathrm{M}=484.4$ vs. $529.8, t(274)=3.29, p=.001, d=.40)$. Significant differences 
were observed for non-overweight participants, $(\mathrm{M}=493.9$ vs. $526.6, t(265)=2.39, p=.018, d$ $=.29$ ), and the differences in intervention effectiveness based on BMI were not significant $(F(1,539)=0.43, p=.511)$. The findings did not vary with gender, age, whether the person had a weight loss goal or did not have one, hunger, timing of last meal or time taken to complete the survey. However, among those who did report having weight loss goals, people who reported higher (vs. lower) weight loss goals had more of a reduction in calories from the interventions in a post-hoc test $(F(1,222)=6.36, p=.012)$.

\section{STUDY 3: SALIENT LABELS AND MERE-REMINDERS WHEN "HEALTHY" OPTIONS ARE HIGH-CALORIE}

In the prior two studies, the available cues (i.e., item sizes in Study 1, listed ingredients in Study 2) were informative for inferring relative calories. Both salient calorie labels and merereminders can trigger a broader process of semantic activation (Collins and Loftus, 1975), leading to greater use of cues generally related to nutrition. Therefore, when people in the first two studies were reminded to consider calories, their choices were more sensitive to these valid cues.

However, people may sometimes also rely on cues that do not directly predict calories, such as organic content (Schuldt and Schwarz, 2010) or brand-name (e.g., the Subway "healthhalo", Chandon and Wansink, 2007). As a result, when interventions have a reminder effect, the impact on choices could be undermined by increasing preferences for healthy-seeming but highcalorie foods. In fact, average calories chosen at Subway (but not other restaurants) actually increased when calorie labeling was introduced in New York (Dumanovsky et al. 2011), although causal conclusions were difficult to draw from this instance because of potential 
confounds. In Study 3, we investigated choices involving a high-calorie option perceived as healthy.

Method.

We observed adult museum-goers choose among a set of four similarly-sized snack packages (0.8 oz. PopChips, 1 oz. Cheetos, 1 oz. Doritos and 2.5 oz. Goldfish). We had access to the museum for two days, and collected all participants we could during that time. This yielded 699 participants, of which three were eliminated because their choice of snack was not observed. During one 30 minute timeslot, an additional 61 participants were instead given a validation survey, in which they were asked to estimate the calories in each snack.

Participants took the same estimation survey containing unrelated mere-reminder manipulations as in Study 1, and chose among the snacks as a reward. The snacks were displayed in rows in open boxes (see Figure 1, right panel and Figure 6), which were rotated every 30 minutes, across four conditions (control, industry-standard icon, calorie information or exercise-equivalent information). An information panel behind each row either displayed just the name, or also included salient objective information (either the number of calories or exerciseequivalents) in 48 pt. Calibri red font. The snack packages all had standard nutrition disclosures printed on the back, but did not display any nutrition information on the front. In all conditions other than the mere-names control, a calorie information sticker of the same size as the industrystandard icon (3/4") was added to the front of the packages. 


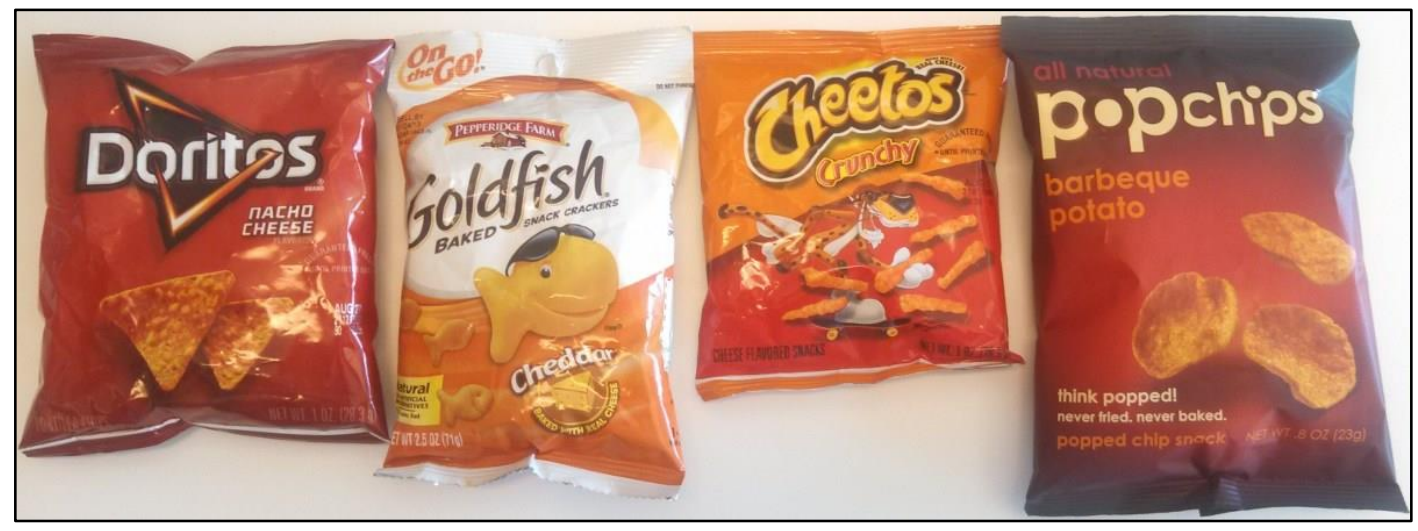

Figure 6: The four snacks used as food choices in Study 3

In all, the study consisted of 12 conditions, with four different information disclosure conditions crossed with three versions of the survey. The study included two control conditions (no information and non-salient industry standard information), and varied the information and mere-reminders. Both the salient information and mere-reminder manipulations were framed in two ways, as calories or as exercise-equivalents.

Results.

We used a set of four similarly-sized snack packages, two of which were estimated to have fewer calories than the other options in a separate validation sample (Popchips 217.4, Goldfish 207.9 vs. Cheetos 271.1, Doritos $257.8 ; t(60)=4.64, p<.001, d=.50)$. Importantly, consumers' calorie perceptions were incorrect, as the heavier Goldfish bag actually had far more calories (350) than the Popchips (100), Doritos (140) or Cheetos (150). 


\begin{tabular}{|l|l|c|c|c|}
\hline \multicolumn{2}{|l|}{} & & \multicolumn{2}{c|}{ Calories taken } \\
Box lid information & Reminder survey version & $N$ & Mean & SD \\
\hline Mere Names & Control & 49 & 157.1 & 121.7 \\
\hline Industry-format icon & Control & 49 & 160.4 & 102.1 \\
\hline Merged Control & Control & $\mathbf{9 8}$ & $\mathbf{1 5 8 . 8}$ & $\mathbf{1 1 1 . 8}$ \\
\hline Salient Calorie & Control & 69 & 184.6 & 115.3 \\
\hline Salient Exercise Equivalent (EE) & $\mathbf{1 3 7}$ & 182.2 & 114.3 \\
\hline Merged Salient Information Only & Calorie reminder & 46 & 196.3 & 114.4 \\
\hline Mere Names & EE reminder & 35 & 175.7 & 119.0 \\
\hline Mere Names & Calorie reminder & 50 & 180.0 & 106.5 \\
\hline Industry-format icon & EE reminder & 50 & 183.4 & 109.3 \\
\hline Industry-format icon & & $\mathbf{1 8 1}$ & $\mathbf{1 8 4 . 3}$ & $\mathbf{1 1 2 . 1}$ \\
\hline Merged Mere-Reminder Only & Calorie reminder & 76 & 187.9 & 115.7 \\
\hline Salient Calorie & EE reminder & 75 & 202.3 & 118.6 \\
\hline Salient Calorie & Calorie reminder & 60 & 181.8 & 117.5 \\
\hline Salient Exercise Equivalent (EE) & EE reminder & 69 & 178.1 & 117.3 \\
\hline Salient Exercise Equivalent (EE) & $\mathbf{2 8 0}$ & $\mathbf{1 8 8 . 0}$ & $\mathbf{1 1 7 . 0}$ \\
\hline Merged Salient Information With Mere-Reminder & $\mathbf{5 9 8}$ & $\mathbf{1 8 5 . 8}$ & $\mathbf{1 1 4 . 8}$ \\
\hline \multicolumn{2}{|l|}{ Any Intervention (Salient Information or Reminder) } &
\end{tabular}

Table 3: Average calories chosen in each experimental cell in Study 3, as well as merged conditions (control, salient information only, mere-reminder only and both interventions).

There was no difference in calories chosen between the two control conditions.

Displaying the accurately-sized industry-format icons did not reduce the average calories chosen, compared to the no-information control $(\mathrm{M}=160.4$ vs. $157.1, t(96)=.14, p=.886, d=.03)$. The two control conditions were therefore combined into a single baseline for subsequent analysis.

There was no difference between calorie and exercise equivalent information, averaging across the survey versions $(\mathrm{M}=191.8$ vs. $180.7, t(415)=.98, p=.329, d=.10)$. Likewise, there was no difference between calorie and exercise equivalent reminders, averaging across the box information versions $(\mathrm{M}=186.3$ vs. $186.8, t(459)=.05, p=.961, d=.005)$. We collapsed the framing versions for subsequent analysis, yielding four means of interest: control, salient information only, mere-reminder only and salient information with mere-reminder (see Table 3).

In Study 3, where the high calorie option was perceived as healthy, neither merereminders nor salient information reduced the calories chosen, in contrast with the prior studies. 
In fact, calories chosen were directionally higher in the salient-information-only conditions, compared to the control conditions $(\mathrm{M}=183.4$ vs. $158.8, t(233)=1.65, p=.101, d=.22)$. Likewise, calories chosen were also marginally higher in the mere-reminder-only conditions, compared to the control conditions $(\mathrm{M}=184.3$ vs. $158.8, t(277)=1.81, p=.071, d=.23)$. The calories chosen in the salient-information-only and mere-reminder-only conditions did not differ $(\mathrm{M}=183.4$ vs. $184.3, t(316)=.06, p=.949, d=.007)$. Overall, prompting consideration of calories (either via salient information or mere-reminder) not only did not reduce calories chosen, but instead resulted in a modest backlash, a 27 calorie, or $17 \%$, increase $(\mathrm{M}=185.8$ vs. $158.8 ; t(694)=2.17, p=.030, d=.24)$.

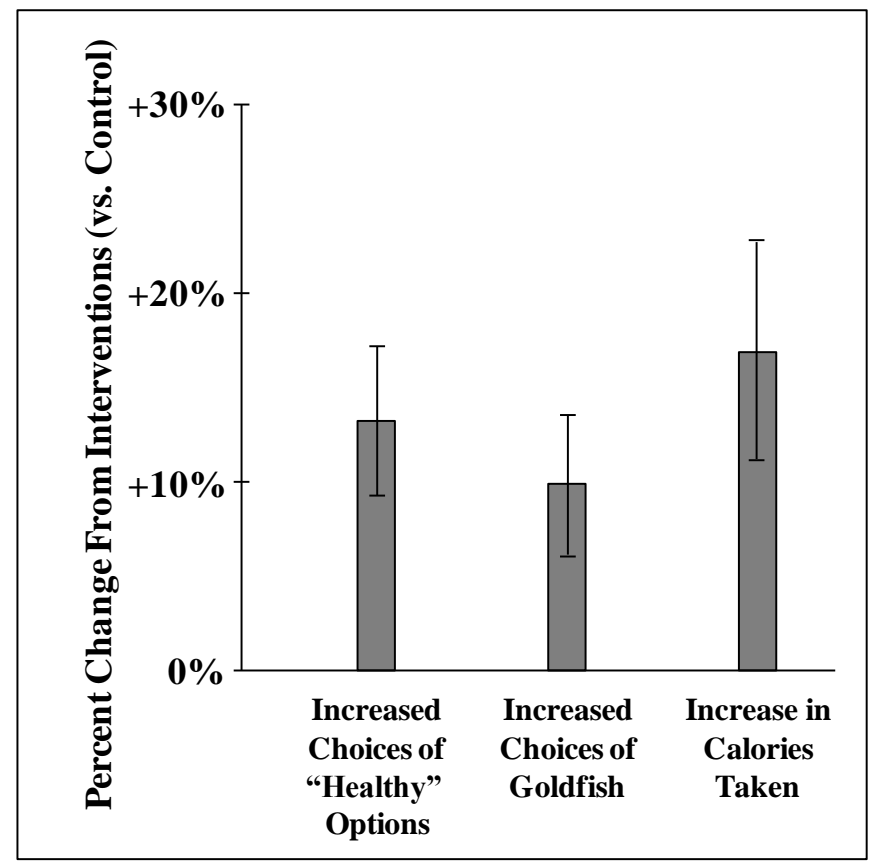

Figure 7: Changes in behaviors in the intervention conditions (relative to control). Vertical lines are $95 \%$ confidence intervals.

A regression analysis revealed similar results (see Appendix VII, Table S3.4). Any salient intervention (i.e. salient information disclosure or non-informative mere-reminders) 
directionally increased calories taken $\left(\beta_{\text {SALIENT }}=+25.06, \mathrm{SE}=13.26, p=.059\right)$, but there was no significant difference between the increase in calories chosen from salient information disclosure alone versus non-informative mere-reminders alone $\left(\beta_{\text {COMPARISON }}=0.41, \mathrm{SE}=6.48, p=.949\right)$,

We attribute the lack of calorie reduction (and, in fact, increase in calories chosen) to an ironic effect of the interventions prompting people to consider calories, and thereby to focus on perceived nutrition (Figure 7). Consistent with this interpretation, the interventions (salient information and mere-reminders) increased choices of the two items typically believed to be healthier relative to the other options. Participants were more likely to choose the two seemingly healthier options in the intervention conditions, compared to the control conditions $(61.2 \%$ vs. $\left.49.0 \%, \chi^{2}(1)=5.22, p=.022, \varphi=.09\right)$. However, this increase in choices of the seemingly healthy options in the intervention conditions was driven by choices of the high-calorie Goldfish (30.8\% vs. $\left.21.4 \%, \chi^{2}(1)=3.54, p=.060, \varphi=.07\right)$, contributing to the increase in calories.

\section{Discussion.}

Study 3 examined a consequential boundary condition of the mere-reminder effect. Since salient calorie disclosures and mere-reminders prompt people to use their pre-judgments about the food-items in their decision making, participants chose more of the option perceived as healthier (i.e., Goldfish) when they encountered salient calorie disclosures or mere reminders. Salient calorie information can therefore backfire when high-calorie foods are seen as healthy, increasing the calories chosen, because of the reminder effect.

Prompting consideration of nutrition (by providing either salient information or merereminders) had similar effects on overweight participants ( $\mathrm{M}=188.2$ vs. $169.5, t(313)=0.98, p=$ $.326, d=.16)$ and non-overweight participants (M = 185.9 vs. $151.1, t(304)=1.89, p=.059, d=$ $.31)$, but BMI did not significantly moderate the results $(F(1,617)=0.37, p=.541)$. The results 
were also robust to differences in gender, age, income, number of years of schooling, ethnicity and having an active health goal.

\section{GENERAL DISCUSSION}

We find that both salient informational interventions and non-informative merereminders have a similar impact, reducing calorie choices. In contrast, we did not find an effect of the industry-standard low-salience information provided in practice, potentially due to the failure to serve as an effective reminder. These findings do not depend on whether the calorie information was framed in terms of calories or translated to exercise-equivalents (contrary to the conclusions of Bleich et al. 2012 and Dowray et al., 2013), and the findings are highly robust across demographics. The results suggest that sufficiently salient information and noninformative mere-reminders both influence choices via a similar attentional and deliberational process, increasing the influence of nutrition-related cues, and fostering self-control.

Purely informational salient disclosure and equally salient prescriptive interventions (such as "multiple-traffic-light" labeling which uses color coding to convey potentially unhealthy ingredients; Roberto and Khandpur, 2014), typically seen as very different interventions, may in

fact both operate via the same reminder processes, with similar effects on self-control. Reducing calories chosen by simply reminding people that they can take smaller portions (Schwartz et al., 2012) may also be due more to the pure reminder effect than to any information conveyed. Likewise, it may be that people are more likely to say they consider calories when provided with a daily calorie recommendation (Wisdom et al. 2010), not because of the improved information 
or increased interpretability, but because of the reminder that the calorie recommendation provides.

These results suggest that the emphasis on information may be misguided. Recently, the FDA has decided to push back the deadline for restaurants and retailer to post calories because of the time required to determine accurate calorie counts to post (Dennis, 2015). Our findings suggest that effective policies should instead focus on salience of disclosures. Providing approximate but salient calorie information is likely to be more effective than an accurate but non-salient disclosure. In fact, when accurate labeling is not feasible, mere-reminders may serve as a useful behavioral intervention, as long as valid cues in the decision environment (such as size or ingredients) signal relative calorie content. However, as illustrated in Study 3, both salient calorie information and mere reminders may be less effective, and could even backfire, when reminders increase the use of cues that favor high-calorie options.

Although we suggest that calorie disclosure often influences choices primarily via reminders rather than by providing missing information, in some specific situations a salient disclosure may instead shift choices by providing informational benefits. According to our account, when people lack valid cues as to the relative calories of the options, but the choice options do not differ substantially in perceived healthiness, mere-reminders will not be effective, while sufficiently salient information can shift choices by providing needed information, reducing calories chosen. In an additional study (provided in the supporting information), we confirm this by artificially creating such a situation, asking people to make hypothetical choices among candy bars with no relative product size information. In this setting, we find no effect of mere reminders and a strong reduction in calories chosen when salient calorie information is provided. Similar results have been found by Burton et al (2006), and may be particularly 
applicable to settings such as first-time restaurant orders, where valid cues and implicit knowledge are particularly likely to be lacking. However, these preconditions for pureinformation effects are less likely to hold in many of the most common calorie-choice settings, including dining at familiar restaurants and purchasing consumer packaged goods.

Our findings may help explain why prior studies of calorie labeling, which differed in visual salience and contextual cues, yielded such inconsistent results. Studies in which calorie information was less visually salient may have had less of an effect on choices, not only because the information was less likely to be processed, but also because the reminder effects documented here would have been suppressed. In fact, this may help contribute to the fact that studies conducted in restaurants have found weaker effects of calorie information than studies conducted in more controlled lab settings (Long et al. 2015), where visual distractions are minimized and even ordinary information manipulations are more likely to be experienced as salient.

Therefore, it is important to note that salience, in our account, represents a psychological state of the decision-maker in processing the stimulus, rather than a fixed characteristic of the stimulus. Thus, an intervention that is sufficiently salient to affect decisions in one context may not have the same effect in another, more distracting context. In particularly, the level of salience that was sufficient for substantial average reductions in calories in the controlled settings of our studies may yield smaller reductions in calories in distracting field settings. Furthermore, newly introduced informational interventions may become less salient to decisionmakers over time, as the labeling format becomes less novel and therefore less noticeable, with a corresponding reduction in the reminder effect. 
Our findings caution policy makers that informational interventions which are effective in one choice situation may be ineffective, or potentially even backfire in another (e.g., when consumer beliefs about nutrition are inconsistent with calorie content), due to the reminder process. This highlights the necessity of experimentally testing proposed informational interventions. More broadly, our results illustrate the importance of considering the unintended broader psychological consequences for decision-making of policy interventions that are intended to merely inform people. 


\section{REFERENCES}

Ainslie, G. (1975). Specious reward: a behavioral theory of impulsiveness and impulse control, Psychological Bulletin, 82(4), 463.

Bartels, D. M. and O. Urminsky (2015) To Know and To Care: How Awareness and Valuation of the Future Jointly Shape Consumer Savings and Spending, Journal of Consumer Research, 41(6), 1469-1485.

Black, E. A. (2014). Menu Labeling: The Unintended Consequences to the Consumer, Food \& Drug Law Journal, 69, 531.

Bleich, S. N., B. J. Herring, D. D. Flagg, T. L. Gary-Webb (2012). Reduction in purchases of sugar-sweetened beverages among low-income black adolescents after exposure to caloric information, American Journal of Public Health, 102(2), 329-335.

Bray, G. A., S. R. Smith, L. de Jonge, H. Xie, J. Rood, C. K. Martin, M. Most, C. Brock, S. Mancuso, L. M. Redman (2012) Effect of Dietary Protein Content on Weight Gain, Energy Expenditure, and Body Composition During Overeating: A Randomized Controlled Trial, Journal of the American Medical Association, 307(1), 47-55

Burton, S., Creyer, E. H., Kees, J., \& Huggins, K. (2006). Attacking the obesity epidemic: the potential health benefits of providing nutrition information in restaurants. American Journal of Public Health, 96(9), 1669-1675.

Cawley, J., C. Meyerhoefer (2012). The medical care costs of obesity: an instrumental variables approach. Journal of Health Economics, 31(1), 219-230.

Chandon, P., B. Wansink (2007). Is obesity caused by calorie underestimation? A psychophysical model of meal size estimation, Journal of Marketing Research, 44(1), 84-99.

Chandon, P., \& Wansink, B. (2007). The biasing health halos of fast-food restaurant health claims: lower calorie estimates and higher side-dish consumption intentions, Journal of Consumer Research, 34(3), 301-314. 
Collins, A. M., E. F. Loftus (1975). A spreading-activation theory of semantic processing, Psychological Review, 82(6), 407-428.

Cutler, David M., Edward L. Glaeser, and Jesse M. Shapiro. 2003. Why Have Americans Become More Obese? Journal of Economic Perspectives, 17(3): 93-118.

Dennis, Brady (2015), Want to know how many calories are in that burger? Sit tight. The FDA has delayed menu calorie count rules. The Washington Post, July 9, 2015

Dowray, S., Swartz, J. J., Braxton, D., \& Viera, A. J. (2013). Potential effect of physical activity based menu labels on the calorie content of selected fast food meals. Appetite, 62, 173-181.

Dumanovsky, T., Huang, C. Y., Nonas, C. A., Matte, T. D., Bassett, M. T., \& Silver, L. D. (2011). Changes in energy content of lunchtime purchases from fast food restaurants after introduction of calorie labelling: cross sectional customer surveys, BMJ, 343 .

Flegal, K. F., M. D. Carroll, B. K. Kit, C. L. Ogden (2012) Prevalence of Obesity and Trends in the Distribution of Body Mass Index Among US Adults, 1999-2010, Journal of the American Medical Association 307 (5), 491-497.

Food Labeling, 79 Federal Register 230 (December 1, 2014) and 79 Federal Register 41 (March 3, 2014).

Harrison, G. W., \& List, J. A. (2004). Field experiments. Journal of Economic Literature, 1009-1055.

Herman, C. P., \& Polivy, J. (2005). Normative influences on food intake, Physiology \& Behavior, 86(5), 762-772.

Hoch, S. J., \& Loewenstein, G. F. (1991) Time-inconsistent Preferences and Consumer Selfcontrol, Journal of Consumer Research, 492-507.

Hoffmann, W., Friese, M., \& Strack, F. (2009). Impulse and self-control from a dual-systems perspective, Perspectives on Psychological Science, 4(2), 162-176. 
Kramer, C. K., B. Zinman, R. Retnakaran (2013). Are metabolically healthy overweight and obesity benign conditions? A systematic review and meta-analysis, Annals of Internal Medicine, 159(11), 758-769.

Levav, J., G. Fitzsimons (2006) When Questions Change Behavior: The Role of Ease of Representation, Psychological Science, 17(3), 207-213.

Long, M. W., D. K. Tobias, A. L. Cradock, H. Batchelder, S. L. Gortmaker (2015). Systematic Review and Meta-analysis of the Impact of Restaurant Menu Calorie Labeling, American Journal of Public Health, 105(5), e11-e24.

Mann, T., \& Ward, A. (2007). Attention, self-control, and health behaviors, Current Directions in Psychological Science, 16(5), 280-283.

Milkman, K., Rogers, T., \& Bazerman, M. H. (2010) I'll have the ice cream soon and the vegetables later: A study of online grocery purchases and order lead time, Marketing Letters, 21 (1), 17-35

Myrseth, K., and A. Fishbach. Self-control a Function of Knowing When and How to Exercise Restraint, Current Directions in Psychological Science 18, no. 4 (2009): 247-252.

Parker, J. R., \& Lehmann, D. R. (2014). How and When Grouping Low-Calorie Options Reduces the Benefits of Providing Dish-Specific Calorie Information, Journal of Consumer Research, 41(1), 213-235.

Roberto, C. A., N. Khandpur (2014) Improving the design of nutrition labels to promote healthier food choices and reasonable portion sizes, International Journal of Obesity, 38 , S25-S33

Rozin, P., Scott, S., Dingley, M., Urbanek, J. K., Jiang, H., \& Kaltenbach, M. (2011). Nudge to nobesity I: Minor changes in accessibility decrease food intake, Judgment and Decision Making, 6(4), 323-332.

Ruderman, A. J. (1986). Dietary restraint: a theoretical and empirical review, Psychological Bulletin, 99(2), 247. 
Schuldt, J. P., \& Schwarz, N. (2010). The 'organic' path to obesity? Organic claims influence calorie judgments and exercise recommendations, Judgment and Decision Making, 5(3), 144-150.

Schwartz, J., Riis, J., Elbel, B., \& Ariely, D. (2012). Inviting consumers to downsize fastfood portions significantly reduces calorie consumption. Health Affairs, 31(2), 399407.

Shen, L., O. Urminsky (2013). Making Sense of Nonsense: The Visual Salience of Units Determines Sensitivity to Magnitude, Psychological Science, 24(3), 297-304.

Sunstein, Cass (2015). Don't give up on fast-food calorie labels. Bloomberg View, November $3,2015$.

Swinburn, B., G. Sacks, E. Ravussin (2009) Increased food energy supply is more than sufficient to explain the US epidemic of obesity, American Journal of Clinical Nutrition, 90(6), 1453-1456.

Tang, D., L. Fellows, A. Dagher (2014) Behavioral and Neural Valuation of Foods Is Driven by Implicit Knowledge of Caloric Content. Psychological Science, 25(12), 21682176.

Weber, E., B. Kirsner, B. (1997). Reasons for rank-dependent utility evaluation, Journal of Risk and Uncertainty, 14(1), 41-61.

Wisdom, J., Downs, J. S., \& Loewenstein, G. (2010). Promoting healthy choices: Information versus convenience. American Economic Journal: Applied Economics, 164-178. 


\section{The "Mere-Reminder" Effect of Salient Calorie Labeling. \\ Unreviewed Supplementary Appendix}

Indranil Goswami and Oleg Urminsky

\section{Contents:}

I. Additional Details for Study 1

II. Additional Details for Study 2

III. Additional Details for Study 3

IV. Supplemental Study A

V. Study Stimuli

VI. Variable Definitions

VII. Tables

VIII. Supplemental Analysis and Moderators 


\section{Appendix I. Additional Details of Study 1}

Method

Participants. The study was conducted in June of 2013 in a large mid-western city, in a public museum. Participants were adult visitors intercepted at a table set up in the hall between exhibits inside the museum. In total, 836 complete adult responses were obtained ${ }^{1}$. The sample was $46 \%$ male, with a median age in the 25 and 34 years old range, and median income was in the $\$ 50,000$ to $\$ 80,000$ range. The average number of years spent in school was 16 years (i.e. some college), with $9.5 \%$ of the visitors reporting only a high school education or less. We calculated BMI scores based on self-reported height and weight. We found that $48 \%$ of the participants were in the healthy range (BMI of 18.5 -24.9) $49 \%$ of the sample was overweight or obese (BMI of 25 or more), and the rest were underweight (BMI under 18.5).

Stimuli. Four different-sized Snickers candy bars, varying in calorie content $(250,130,80$, and $45)$, were offered to participants as compensation for completing a brief survey questionnaire (see figure S1.2). The survey questionnaire contained the mere-reminder manipulation (figures S1.4-S1.6). Interspersed in the questionnaire, which contained seven numerical estimation questions, were three questions about food items unrelated to the Snickers bars: either estimating the calorie content (calorie reminder), or the number of minutes of various physical activities required to burn the calories (exercise equivalent reminder), or a non-nutrition trivia questions (control).

The candy bars were kept in 4 closed boxes, one for each type. Participants had to remove the lid to take a candy bar from its box. On each of the lids, we presented the different information that comprised four conditions (figure S1.1).

1. Mere Names: Names and pictures were shown but no additional information was presented.

2. Industry-format calorie information: A common industry $3 / 4$ " "chiclet" disclosure format ${ }^{2}$ was presented, as well as names and pictures (figure S1.3).

3. Salient Calorie information: The calorie content was displayed in a salient format (38 pt. font size), as well as names, pictures and the industry-format chiclet.

4. Salient Exercise Equivalent information: The minutes of running required to burn the calories was displayed in a salient format (38 pt. font size).

Procedure. The study employed a 3(reminder survey version) x 4 (box lid information) fullfactorial design. The questionnaires containing the various reminder manipulations were prerandomized in a stack. The box-lid information conditions were rotated every 30 minutes by changing the lids on the boxes. The recruitment script described the study as an estimation task, and participants answered the questions based on their own opinion, and also estimated the responses of the average participant who took the study. Participants answered the survey questions before choosing the candy bar as their reward, which enabled us to study the effect of the reminders on their choice.

\footnotetext{
${ }^{1}$ Choices of two participants were not recorded, and therefore were excluded from the analysis.

2 "Mars launches 'What's Inside"' Candy Industry, Nov 2008, v. 173, p.10-11
} 
The key dependent measure was the snack choice each participant made after completing the survey. After the participant handed over the filled-in questionnaire to a research assistant, they were asked to help themselves to a candy of their choice for participating in the research. The research assistant unobtrusively wrote down which candy bar, if any was chosen, along with the experimental condition and time of day in the corner of the questionnaire.

Although participants were instructed to pick one bar candy for their participation, three participants took more than one, and we coded the calories taken accordingly. Some participants chose not to take a candy bar, and the calories for these participants were recorded as zero. The research assistant also unobtrusively noted if participants' choices were influenced by children with them, or the participant mentioned any constraint on their choices (e.g. a nut allergy).

Results and Analysis. Table S1.1 (Appendix VII) shows the average calories chosen in each cell of the experiment. The average amount of calories chosen when participants estimated calories of unrelated food items (calorie mere-reminder) was not different from when participants estimated minutes of physical activities required to burn calories (exercise-equivalent merereminder) in unrelated food items (148 vs. 136 respectively, $t(560)=1.37, p=.17)$. Therefore, these two cells were merged into a single mere-reminder condition in the subsequent analysis.

The industry-format icon on the box lids did not reduce calories compared to the nodisclosure control condition (164 vs. 153 respectively, $t(372)=1.11, p=.26$ ) and these two conditions were therefore also merged into a single "minimal disclosure" condition. Lastly, calories chosen with salient calorie information (133) did not differ significantly from salient exercise equivalent information $(141 ; t(460)<1)$ and these two conditions were combined into a salient information disclosure condition for our subsequent analysis.

We conducted a series of multivariate regressions to examine the effects of the experimental conditions on calories chosen. We predicted calories chosen based on three variables, which capture the key differences across conditions:

Salient intervention: 1 if either salient disclosures or mere-reminders were present, 0 otherwise

Both interventions: 1 if both salient disclosures and mere-reminders were present, 0 otherwise)

Intervention comparison: -1 if salient information only, +1 if mere-reminder only, 0 otherwise).

The first regression analyzed the results for the full study (table S1.2). As indicated by the constant, in the control conditions (minimal disclosure and no-reminder), participants took 171.81 calories on average (table S1.2, column 1). Overall, salient interventions reduced calories chosen $(\beta=-23.30, t=-2.31, p=.02)$. Providing both interventions (salient disclosures and mere-reminders) lead to a directional further reduction in calories chosen, but the difference was not statistically significant $(\beta=-11.14, t=-1.15, p=.25)$. We found no effect of the intervention contrast $(\beta=4.18, t<1)$, suggesting that there was no significant difference 
between the decrease in calories chosen from providing salient information on the box lids or from providing mere-reminders in the survey.

These findings are robust to other regression specifications (table S1.2, columns 2-4). It is particularly important to note that the findings persist when we control for time-of-day fixed effects (10 am to $12: 30 \mathrm{pm} /$ before lunch vs. $12: 30 \mathrm{pm}$ to $2 \mathrm{pm} /$ early afternoon vs. 2 pm to $3: 30$ $\mathrm{pm} /$ late afternoon vs. $3: 30 \mathrm{pm}$ to $5 \mathrm{pm} /$ early evening), to control for any variation in desire for candy bars over the course of a day. Likewise, the results are unchanged when we exclude thirty-one participants whose data noted as potentially problematic by the RA. These were participants who either did not look at the box lid when making their choice, mentioned having an allergy to nuts, expressed suspicion about the motives of the study, had research-related training (e.g. post-doctoral scholar or professor), or whose choices were made by or were influenced by children. The results are also unchanged when we exclude only those eighteen participants whose decisions were noticeably influenced by children accompanying them in the museum.

We also investigate whether participants' weight moderated the results. Overweight participants $(\mathrm{BMI}>25)$ took 181 calories in the control conditions (i.e., when they were not provided with any salient disclosures or mere-reminders). When the overweight participants were provided with either salient disclosures or mere-reminders, they significantly reduced their calorie choices, to $136(t(362)=3.41, p<.001)$. Non-overweight participants also chose directionally fewer calories (161 vs. $145, t(374)=1.06, p=.29)$ when provided with salient information or mere-reminders, but the results were not significant. While the effect of the interventions was directionally weaker for lower BMI participants, a regression analysis did not find a significant interaction with $\operatorname{BMI}(F(1,736)=1.95, p=.16)$

Similarly, the findings were not significantly moderated by gender, age, income, number of years of schooling, or ethnicity (Appendix VIII, tables 2a-2f).

\section{Appendix II. Additional Details of Study 2}

We conducted a series of online studies (first Study $2 \mathrm{a}$, then a pre-test Study $2 \mathrm{~b}$ and Study 2c) with hypothetical choices of unbranded sandwiches ${ }^{3}$, to examine the effect of information and mere-reminders on calories chosen. The studies were collected at different times, using the calorie information that was publicly available at each time ${ }^{4}$, and tested a variety of different information and mere-reminder manipulations. In the paper, for ease of exposition, we report data from Study 2c, which is more recent and which used a simpler design. However, in this supporting online material, for the sake of completeness, we present a combined analysis of all the data collected (Studies $2 \mathrm{a}, 2 \mathrm{~b}$ and $2 \mathrm{c}$ ).

\section{Method.}

\footnotetext{
${ }^{3}$ Taken from: http://www.mcdonalds.com/us/en/food/full_menu/full_menu_explorer.html and http://nutrition.mcdonalds.com/getnutrition/nutritionfacts.pdf

${ }^{4}$ The actual calorie information for the sandwiches changed between the two studies
} 
Participants. The studies were conducted with online participants from Amazon Mechanical Turk $(\mathrm{n}=1361)$. Only adults aged 18 or above could participate in the study, and data from participants who took the survey more than once or who failed an attention check were deleted before analysis was conducted.

The mean age of participants was 33.58 years, and 52\% were female. Forty percent of the participants in the study reported having a weight loss goal, with a median weight loss goal, among those who had one, of losing $10 \mathrm{lbs}$. We calculated BMI scores based on self-reported height and weight. We found that $47 \%$ of the participants were in the healthy range, $50 \%$ were overweight or obese, and the rest were underweight. Therefore, this study had a similar profile of participants as the previous study.

Stimuli. Pictures of six actual McDonalds' sandwiches were shown as choice options. In the first wave (Study 2a), the sandwiches ranged from 380 to 620 Calories. In the second wave (Studies $2 \mathrm{~b}$ and $2 \mathrm{c}$ ) the sandwiches ranged from 350 to 670 Calories. The pictures accurately depicted the relative sizes of the sandwiches, and also displayed the name of the sandwich along with the ingredients (see Figures S2a.1 and S2b.1). However, participants were not informed that the sandwiches were from McDonalds, and the stimuli presented the choices as unbranded food items.

In the salient information conditions, participants were shown either calorie information, or the minutes of running needed to burn an equivalent amount of calories ("exercise equivalent"), or both items of information. Salient information was presented in bold 14-point font, with an explanation of the information in red font (figures S2a.2 - S2a.4; S2b.3 - S2b.5). In the second wave, a non-salient industry-format condition was also included, in which participants were shown calorie information in the same font (10-point) as the ingredients (figure S2b.2).

Multiple mere-reminder manipulations were tested. In the first wave, a random group of participants were asked to estimate either the total calories in a 6-inch personal pan cheese pizza (a picture of the pizza was shown), or the total daily calories recommended by USDA for their profile (i.e., their age, gender and activity level), or the number of minutes required to burn 300 calories running on a treadmill (figures S2a.5 - S2a.7). In a separate mere-reminder manipulation, a different random group of participants was provided with information on total daily recommended calories for various age-gender combinations, and were then asked to estimate the total daily calories appropriate for themselves (figure S2a.8).

In the second wave, the mere-reminder manipulation involved asking participants to estimate either the calories in the sandwiches, or the minutes of running on a treadmill that would burn off the calories in the sandwiches (figures S2b.6 and S2b.7). The pretest in the second wave also had a mere-reminder manipulation similar to the first wave, in which participants were asked to guess the minutes of running on a treadmill required to burn either 300 or 700 calories.

Lastly, in the first wave of the study, two additional conditions were tested, in which participants saw both the mere-reminder manipulation and the salient calorie information, in bold 
14-point font. The two mere-reminders tested were estimating the total daily calories recommended for their age, gender and activity level by USDA dietary guidelines (figure S2a.6) and estimating the number of minutes required to burn 300 calories running on a treadmill (figure S2a.7). Participants in these two conditions then chose among six different sandwiches that had salient calorie disclosures along with their names and ingredients (as shown in figure S2a.2).

Procedure. The study was introduced as a survey about how people think about the choices they make, and all the waves had a simple between-subjects design, with each participant making one sandwich choice. Participants were randomly assigned to one of the conditions, and were asked to indicate their choice of sandwich for lunch. After participants indicated their choice, they were asked a few follow-up questions.

Results and Analysis. Table S2.1 (Appendix VII) shows the average calories chosen in each cell of the study, broken out by each wave of the study. An omnibus F-test revealed no difference in the calories chosen in any of the reminder conditions across the two waves of the study $(F(5$, $439)<1)$ and therefore these cells were merged into a single reminder condition. The effect of salient calorie information, salient exercise equivalent information or both were marginally different in this setting $(F(2,352)=3.08, p=.05)$. Specifically, disclosing both exercise equivalents and salient calories reduced the calories taken, relative to only presenting salient calories (485 vs. $454, t(227)=2.16, p=.03)$. Finally, in this distraction-free setting even nonsalient disclosures did reduce calories significantly, compared to control (510 vs. 536, $t(453)=2.45, p=.01)$.

Combining all the data from the various waves in this study, we find that providing salient information (i.e. salient calories or salient exercise equivalents or both) yielded significantly fewer calories chosen than in the control conditions (466 vs. 536, $t(608)=7.95$, $p<.00001)$. Salient calorie information alone resulted in a significant reduction in calories taken compared to non-salient information ( 485 vs. $510, t(323)=1.98, p=.05)$, as did salient exerciseequivalent information alone $(457$ vs. $510, t(324)=4.18, p<.00001)$. Furthermore, consistent with the mere-reminder effect, even non-informative mere-reminders significantly reduced calories taken, compared to non-salient information $(490$ vs. $510, t(643)=2.19, p=.03)$. The reduction in calories chosen with mere-reminders was $80 \%$ of the effect obtained with salient calorie disclosures alone, and $45 \%$ of the effect from presenting any salient information.

A regression analysis (see table S2.2) predicting calories based on salient intervention, both interventions and intervention comparison supports these conclusions. Salient interventions reduced the calories chosen, combining mere-reminders and salient disclosure yielded an even larger reduction, and salient disclosures were significantly more effective than mere-reminders.

The effect of salient intervention on calories chosen was marginally moderated by BMI (Appendix VIII, table 3a, $F(1,797)=2.94, p=.09)$. While both overweight (BMI > 25) as well as non-overweight participants took fewer calories when they were provided with either salient disclosures or mere-reminders, the reduction in calories chosen was strongly significant for overweight participants (485 vs. $533 ; t(398)=4.32, p<.0001$ ), but was weaker for non-overweight participants $(503$ vs. $524, t(399)=1.83, p=.07)$. 
Although the effect of salient intervention (salient disclosures or mere-reminder) was not moderated by whether participants had a weight loss goal (Appendix VII, table 3b), among those who had a weight loss goal, the intervention was marginally more effective for those who had a higher weight loss goal amount $(F(1,831)=2.81, p=.09$, Appendix VII, table 3c). Participant's gender, age, or activity level did not moderate the results (see Appendix VIII, tables 3d - 3f). The results were also not moderated by the total time spend taking the survey, as tested in Study 2c (Appendix VIII, table 3g).

\section{Appendix III. Additional Details of Study 3}

\section{Method}

Participants. The study was conducted in the same mid-western public museum as the previous field studies in August 2013. Participants were adult visitors in a public museum, and, in total, 696 complete adult responses were obtained. ${ }^{5}$ The sample was $57 \%$ female, had a median age between 25 and 34 years, and a median income between $\$ 50,000$ and $\$ 80,000$. The mean time spent in school was 16 years, and $10 \%$ of the visitors had only a high school education or less. . Finally, based on BMI scores calculated from self-reported height and weight, $51 \%$ of the sample was overweight or obese, $47 \%$ were in the healthy range, and the rest were underweight.

Stimuli. The study design was similar to Study 1, and followed a similar protocol. There were two orthogonal manipulations: mere-reminders embedded in a survey, and salient information disclosures using labels on the boxes containing the food item. A set of four salty-snacks (Goldfish: 350 calories, Cheetos: 150 calories, Doritos: 140 calories, Popchips: 100 calories) were used as choice options (figure S3.1). Although the content in these packages differed in weight (Goldfish: $2.5 \mathrm{oz}$, Cheetos: $1.0 \mathrm{oz}$, Doritos:1.0 oz, Popchips: $0.8 \mathrm{oz}$ ), a pre-test revealed that the packages were perceived to have similar sizes. The four snacks were kept in open cardboard boxes so that they were clearly visible to the participants (figure S3.2).

As in Study 1, four information conditions were used: mere-names, industry-format icon disclosure, salient calorie, and salient exercise-equivalents. The industry-format icon disclosure was implemented using stickers which were pasted on the front of the packages. Therefore, we used two sets of snacks - one with these stickers (used in industry-format icon, salient calorie, salient exercise-equivalent disclosure conditions) and one without (used in the mere-names control condition). The salient information disclosures were implemented with paper labels hanging from the rear wall of the cardboard boxes containing the snacks.

The reminder manipulation was implemented in the survey questionnaires, administered before participants chose a snack. The same questionnaire as in Study 1 was used, containing several numerical estimation questions, interspersed within which were three questions related to estimating either the calorie content of unrelated food items (calorie reminder), or the number of minutes of various physical activities required to burn off calories in unrelated food items

\footnotetext{
${ }^{5}$ Choices of three participants were not recorded, and therefore were excluded from the analysis.
} 
(exercise equivalent reminder), or non-nutrition trivia questions about the unrelated food items (control).

Procedure. The study employed a 3(reminder survey version) x 4 (information on paper labels) full-factorial design. Adult visitors to the museum were approached to participate in a short estimation survey in exchange for a snack as reward. The four disclosure conditions were rotated every 30 minutes, and the three questionnaire types were randomized by collation, and administered within each disclosure condition.

In between administering the regular experimental conditions, we asked a separate randomly chosen group of participants to view the stimuli and estimate the actual calories contained in each snacks, and answer three other related questions (figure S3.4). This was done to test how the population of museum-goers perceived the relative calorie content and relative healthiness of the snacks used in the study.

Similar to study 1, participants' choices were unobtrusively observed and recorded. One participant took more than one snack, and the calories taken were coded accordingly. Similarly, we also noted if choices were made by or influenced by children, or if any other factors influenced participants' choices.

Results and analysis. The separate group of participants $(\mathrm{n}=61)$ who were asked to estimate the calorie content of the snacks perceived Goldfish and Popchips to have the fewest calories, and Cheetos and Doritos to the most Calories (average estimates: Goldfish 208; Popchips 217; Doritos 258; and Cheetos 271). There was no statistical difference between the estimates of Popchips and Goldfish, and between the estimates of Cheetos and Doritos, however, paired ttests revealed that the estimated calories in the latter two items were each significantly higher than that in the former ( 271 vs. $208, t(60)=3.96 ; p<.001 ; 258$ vs. $208, t(60)=3.39 ; p<.001$; 271 vs. $217, t(60)=3.43 ; p<.01 ; 258$ vs. $217, t(60)=2.59 ; p<.05)$. Therefore, participants mistakenly perceived Goldfish to have the least calories, even though it actually had the most calories, largely due to the heaver weight of the package $(2.5 \mathrm{oz}$. vs. $0.8-1 \mathrm{oz}$. for the rest of the options).

The amount of calories chosen as the snack reward in the calorie mere-reminder condition (when participants estimated calories of unrelated food items in the survey) was not different from the calories chosen in the exercise-equivalent mere-reminder condition (when participants estimated minutes of physical activities required to burn calories) - 186 vs. 187 respectively $(t(459)<1)$. Therefore, these two cells were merged into a single mere-reminder condition in the subsequent analysis. The industry-format icon did not change the calories taken, compared to the no-disclosure control condition (175 vs. 176 respectively, $t(277)<1$ ). These two conditions were also merged, into a single minimal-disclosure condition. Likewise, the number of calories taken with salient calorie disclosures were similar to the number taken with salient exercise-equivalent disclosures $(192$ vs. $181, t(415)<1)$ and these cells were merged into a single salient-information condition. 
Table S3.1 (Appendix VII) shows the calories taken in each of the experimental cells in this study. We also conducted regression analyses, predicting choices of an item perceived as healthy (i.e., Popchips or Goldfish) as well as calories chosen, based on salient intervention, both interventions and intervention comparison (see Appendix VI for variable definitions). As seen in table S3.2 (column 1), salient interventions (salient disclosures or mere-reminders) lead to a significant increase in the probability of choosing a snack perceived to be healthy $(\beta=.48, z=$ $2.0, p=.04)$. This means over twice as many participants choose either Goldfish or Popchips when they saw salient information or experienced a mere-reminder. There was no statistically significant difference from providing both interventions (versus just one), and there was no significant difference between the effects of salient information and mere-reminders. As a result, salient interventions (salient information or mere-reminders) caused a directional increase in the choice of Goldfish (table S3.3, column $1, \beta=.43, z=1.57, p=.11$ ), resulting in participants choosing 25 more calories, on average (table S3.4, column $1, \beta=25.06, t=1.89, p=.06$ ). Providing both salient information and mere-reminders did not increase calories chosen any further $(\beta=4.60, t<1)$. Furthermore, there was no significant difference between the effects of salient information and of mere-reminders $(\beta=0.41, t<1)$.

These findings are robust to other regression specifications. In particular, the findings persist when we include time of day fixed effects (10 am to 12:30 pm/before lunch vs. 12:30 pm to $2 \mathrm{pm} /$ early afternoon vs. $2 \mathrm{pm}$ to $3: 30 \mathrm{pm} / \mathrm{late}$ afternoon vs. $3: 30 \mathrm{pm}$ to $5 \mathrm{pm} /$ early evening), to control for any variation in desire for the snacks over the course of a day.

Likewise, the results (tables S3.2 - S3.4) are unchanged, or slightly stronger, when we exclude either 69 participants who were recorded as potentially problematic (e.g., expressed suspicion about the motive of the study, or were influenced by children with them) or just the 59 participants whose decisions were noticeably influenced by children accompanying them in the museum.

Overweight participants $(\mathrm{BMI}>25)$ took 170 calories in the minimal-information noreminder conditions. When these participants were provided with either salient information or mere-reminders, the calories were slightly higher (188), although the difference was not significant $(t(313)<1)$. Non-overweight participants took 151 calories in the minimalinformation no-reminder conditions, but took marginally more (186) when provided with either salient information or mere-reminders $(t(304)=1.89, \mathrm{p}=.06)$. Salient interventions increased calories for both overweight and non-overweight participants, and BMI did not significantly moderate the results $(F(1,617)<1$, table 4a Appendix VIII).

In this study participants were asked which goals, if any, they were actively working towards, from a list of four options: financial, health, family/relationship or spiritual. Reporting an active health goal did not moderate the effect of salient disclosures or mere-reminders on calorie choices. Similarly, no moderation was found with the gender, age, income, number of years of schooling, or ethnicity (see Appendix VIII, tables 4b-4g). 


\section{Appendix IV. Supplemental Study A}

In this additional study, we explored a potential boundary condition: situations in which people do not have reliable cues about the calories in the food options. To construct such a setting, participants did not see the actual food items. Instead, in an online survey, participants were shown pictures of the items that were not to scale, and were in fact similar in size, despite actual differences. In this kind of setting, where seeing the packaging does not provide people with diagnostic information about the weight or the calories but all items are similar in perceived health (unlike Study 3), prompting people to consider nutrition via mere-reminders is unlikely to change their choices among the undifferentiated items. In contrast, when consumers have no nutritional cues to base their decision on, providing sufficiently salient calorie content can have an information effect, helping consumers to distinguish among the options, and shifting choices to lower calorie foods.

\section{Method}

Participants. Members of paid survey panels, recruited via Qualtrics, participated in this study. The survey was appended at the end of unrelated marketing research surveys, which paid the participants a fixed base payment. Six participants reported an age lower than 18 years, and they were removed from the data prior to analysis, leaving 985 complete and valid responses.

Respondents' ages ranged between 18 and 76 years, with a median age of 31. Fifty-three percent of the sample was female. Based on BMI calculated from their self-reported height and weight, $48 \%$ of the sample was overweight or obese, $45 \%$ were in the healthy range and the rest were underweight. Based on the reported ZIP codes, the median annual household income in participants' residential area was $\$ 60,127$.

Stimuli and Procedure. Participants read a scenario similar to the methods of Studies 1 and 3, in a museum where they could take part in a short survey in exchange for a snack. Participants were shown four options (Snickers, 280 Calories; Hershey's Bar, 210 Calories; Chips Ahoy!, 140 Calories; and M\&M 70 Calories) to choose from, and were randomly assigned to one of the between-subjects intervention conditions. The conditions varied the information that was presented alongside the options, but the picture-sizes of the options remained the same across conditions (see figure SA.1).

The various conditions tested in the study were: no disclosure, salient calorie disclosure, salient exercise equivalent disclosures (minutes of biking or running required to burn off calories in the focal choice items), mere-reminder interventions (estimating either the calories in the focal choice items, or estimating the minutes of exercise required to burn off the calories in the focal choice items), as well as the combination of salient calorie information mere-reminders. See figures SA. 2 - SA.9 to see the stimuli used for these experimental cells.

Results and Analysis. An omnibus ANOVA revealed no differences in the calories chosen in the three salient information conditions (calorie, running or biking; $F(2,324)<1$ ), and therefore, these cells were merged into a single salient-information condition. Similarly, there were no differences in calorie chosen across the three versions of the mere-reminders $(F(2,322)<1)$ and 
these cells were also merged into a single mere-reminder condition. Likewise, there was no difference between conditions in which biking vs. running mere-reminders were paired with calorie-information $(\mathrm{F}(1,217)=1.38, \mathrm{p}=.24)$, and these two conditions were merged into a single reminder-plus-information condition.

When participants were asked to estimate the caloric contents of the choice options, their perceived ordinal ranking was incorrect $\left(M_{\text {Snicker }}=237>M_{M \& M}=207>M_{\text {Hershey's }}=203>\right.$ $\mathrm{M}_{\text {ChipsAhoy! }}=199$ ). Snickers were estimated to have significantly more calories than the other three snacks, but the perceived average difference in calories between Snickers and the other options was substantially underestimated (estimate $\Delta=34$ vs. actual $\Delta=140$ ). Likewise, the range of calories was vastly underestimated. The difference between the Snickers and the lowest-calorie item (M\&Ms) was 210 calories; however the maximum perceived difference between Snickers and the estimated lowest calorie item (Chips Ahoy!) was only 38 calories. This confirms that the stimuli used created an environment with minimally diagnostic cues, leading to the erroneous perception that the calories (and therefore presumably the nutrition) of the items was similar. While salient information can correct this misperception, mere-reminders cannot.

The average calories chosen in the control (no-information, no-reminder) condition was 208 calories. When salient information disclosures were used, the calories chosen dropped to $170-$ a significant reduction compared to no information $(t(434)=3.8, p<.001)$. However, mere- reminders, which could not correct the stimuli-induced misperception, did not affect the calories taken $(210$ vs. $208, t(432)<1)$. Providing both mere-reminders and salient information reduced calories taken to approximately the same extent as salient information disclosures alone (166 vs. 170). These results were not moderated by BMI, health goals, age, gender, and income.

This study demonstrates that salient information can be more effective than merereminders in those situations where consumers lack cues as to the nutrition or calories in foods, and therefore misperceive their options as more similar than is true. This misperception can be corrected by salient information, while prompting people to consider nutrition, via the merereminder, will not have an effect in such cases.

A key aspect of this study was that no calorie information was available about the products in the mere-reminder conditions. In practice, most commercial packaging is required to display the nutrition information panel. It would be useful for future research to determine if mere-reminders would be effective in prompting people to read the nutrition panel when viewing unfamiliar products with non-diagnostic packaging. 
Appendix V. Study Stimuli

\section{Study 1 Materials}

Figure S1.1: Transparent boxes with lids containing information disclosures.

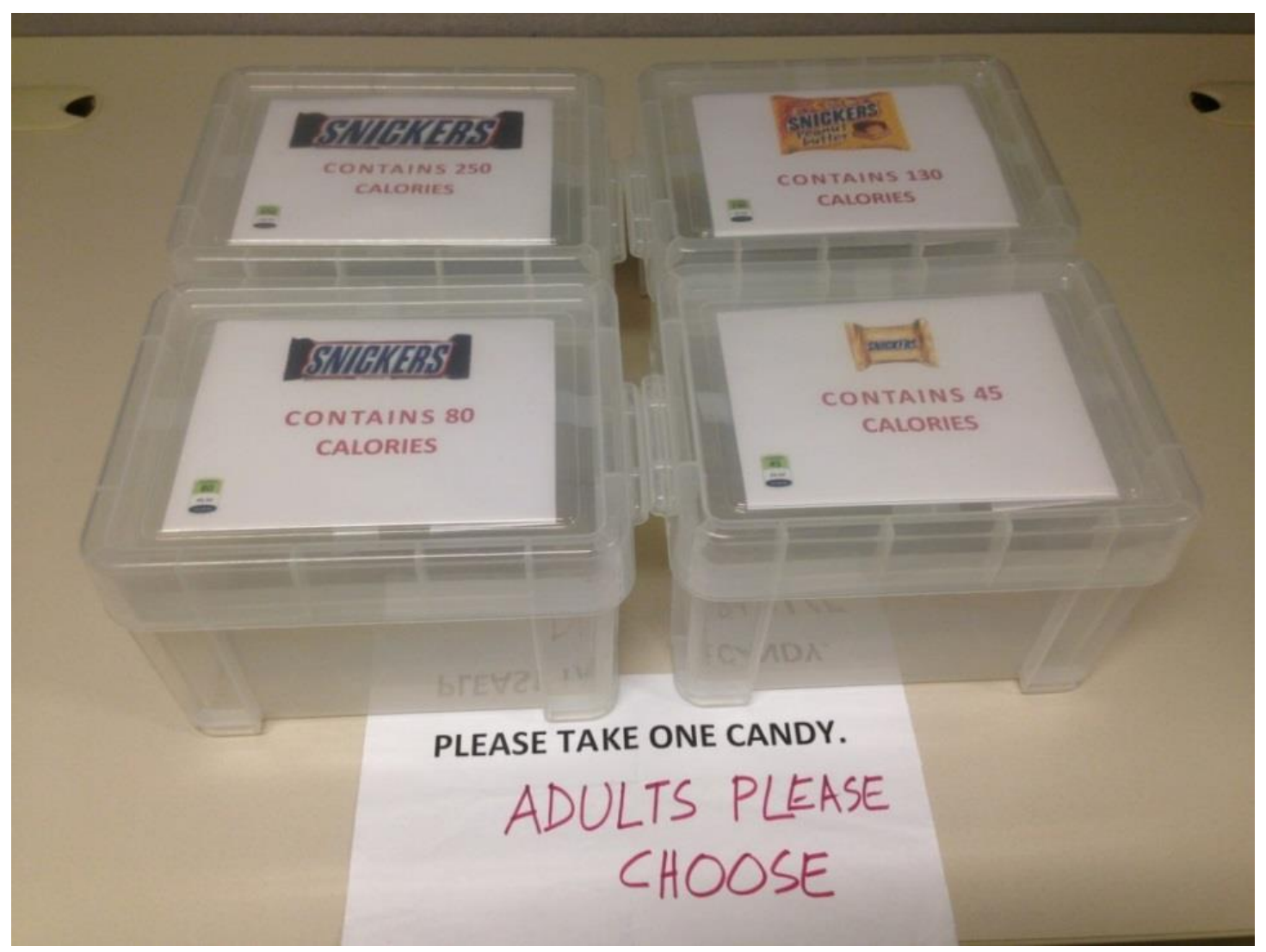


Figure S1.2: Four different versions of the lids (1=Control, 2=Disclosure using industry format, 3=Salient Calorie disclosure, 4=Salient Exercise Equivalent disclosure)

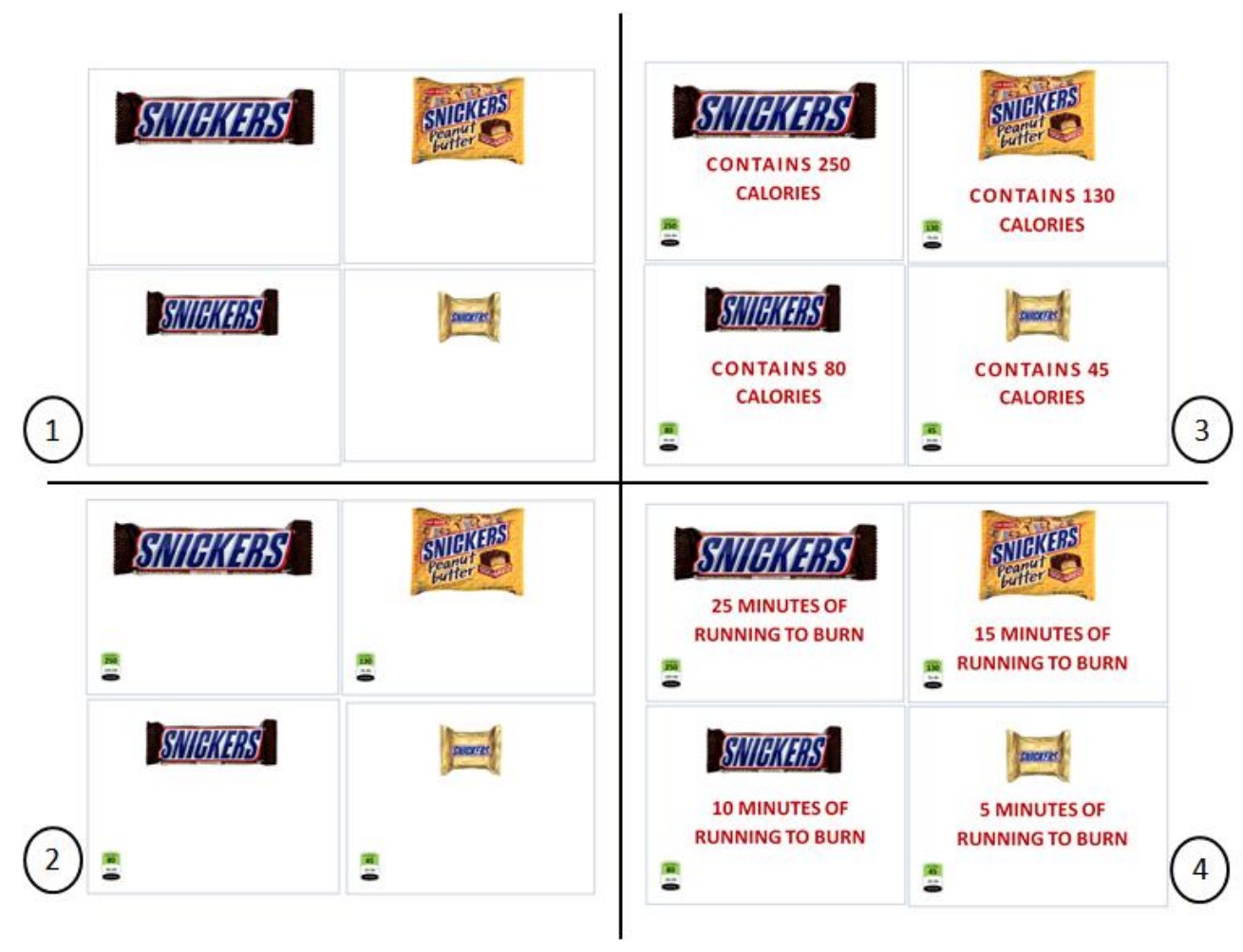

Figure S1.3: A close-up of the industry format disclosure used in the study (left panel), compared to the disclosure format used in a real snack package (right panel)
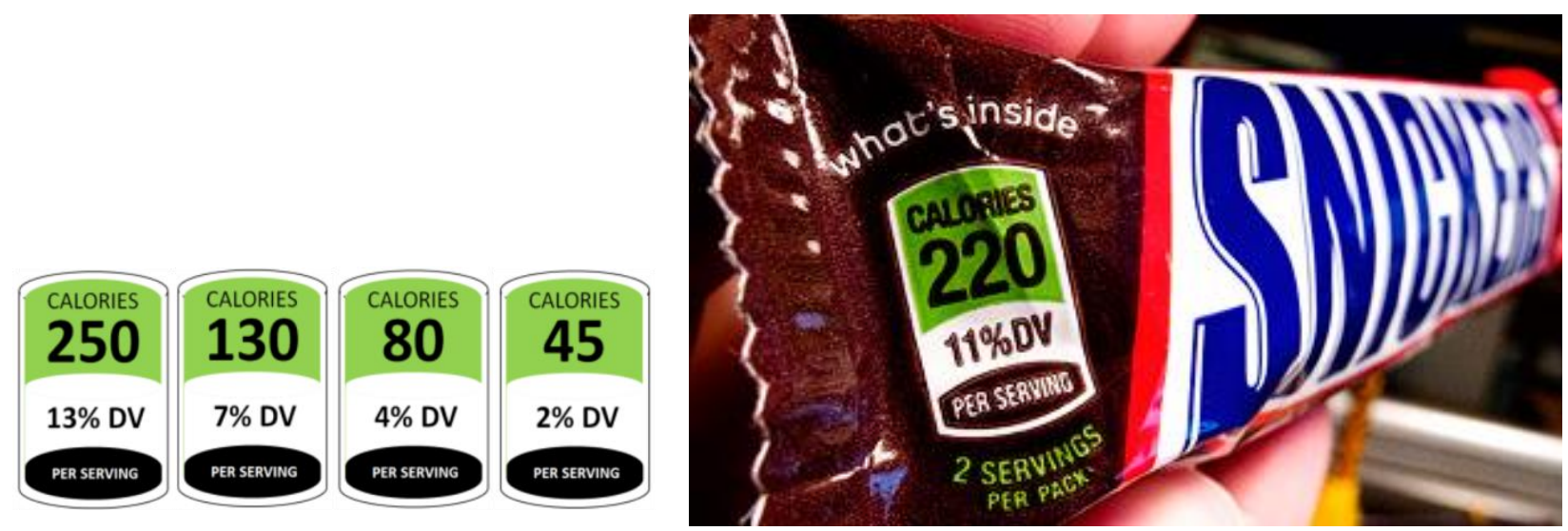
Figure S1.4: Manipulation for Calories Reminders (Survey Questionnaire)

\begin{tabular}{|c|c|c|c|}
\hline \# & Questions & Your Answer & Units \\
\hline 1 & What is the GDP of United States of America? & & Trillion \\
\hline 2 & How many calories in total are there in a McDonald's Big Mac? & & Calories \\
\hline 3 & How many people does the Wal-Mart employ in the US? & & Thousands \\
\hline 4 & How many voting members are there in the US House of Representatives? & & - \\
\hline 5 & How many calories in total are there in a half cup serving of vanilla ice cream? & & Calories \\
\hline 6 & How many US car brands do Ford Motors currently own? & & - \\
\hline 7 & How many calories in total are there in a standard sized Blueberry Muffin at Starbucks? & & Calories \\
\hline
\end{tabular}

Figure S1.5: Manipulation for Exercise Equivalent Reminders (Survey Questionnaire)

\begin{tabular}{|c|c|c|c|}
\hline \# & Questions & Your Answer & Units \\
\hline 1 & What is the GDP of United States of America? & & Trillion \\
\hline 2 & How many minutes of running on a treadmill will burn the calories in a McDonald's Big Mac? & & Minutes \\
\hline 3 & How many people does the Wal-Mart employ in the US? & & Thousands \\
\hline 4 & How many voting members are there in the US House of Representatives? & & - \\
\hline 5 & How many minutes of normal walking will burn the calories in a half cup serving of vanilla ice cream? & & Minutes \\
\hline 6 & How many US car brands do Ford Motors currently own? & & - \\
\hline 7 & How many minutes of leisure biking will burn the calories in a standard sized Blueberry Muffin at Starbucks? & & Minutes \\
\hline
\end{tabular}

Figure S1.6: Manipulation for No-Reminder/Control condition (Survey Questionnaire)

\begin{tabular}{|c|c|c|c|}
\hline \# & Questions & Your Answer & Units \\
\hline 1 & What is the GDP of United States of America? & & Trillion \\
\hline 2 & How many sesame seeds are there on a McDonald's Big Mac bun? & & - \\
\hline 3 & How many people does the Wal-Mart employ in the US? & & Thousands \\
\hline 4 & How many voting members are there in the US House of Representatives? & & - \\
\hline 5 & Approximately, how many licks are required to finish off one scoop of vanilla ice cream? & & - \\
\hline 6 & How many US car brands do Ford Motors currently own? & & - \\
\hline 7 & How many states in the US have an Official State Blueberry Muffin? & & - \\
\hline
\end{tabular}




\section{Study 2a Materials}

Figure S2a.1: Control Condition

1

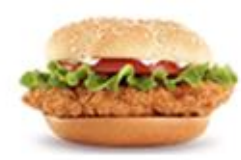

Premium Crispy

Chioken Classio

Sandwich

Crispychicken breast filet

Green Lettuce

Slice of Tomato

Mayonnaise dressing
2

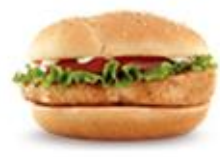

Premium Grilled

Chicken Classic

Sandwich

Grilled chicken breast filet

Green Lettuce

Slice of Tomato

Mayonnaisedressing
3

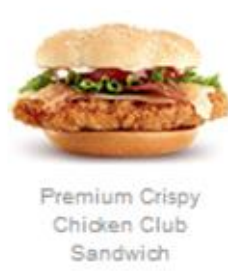

Crispychicken breast filet

Smokedbacon

Swiss cheese

Green Lettuce

Slice of Tomato
4

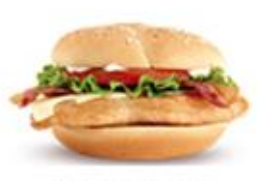

Premium Grilled

Chidien Club

Sandwich

Grilled chicken breast filet

Smoked bacon

Swiss cheese

Green Lettuce

Slice of Tomato
5

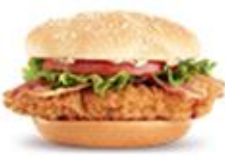

Premium Crispy

Chioken Ranch BLT

Sandwich

Crispychicken breast filet

Smoked bacon Creamy ranch sauce

Green Lettuce

Slice of Tomato
6

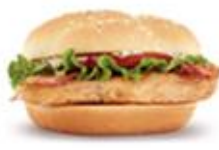

Premium Grilled Chioken Ranch BLT Sandwich

Grilled chicken breast filet Smoked bacon Creamyranch sauce Green Lettuce Slice of Tomato

Figure S2a.2: Salient Calorie Disclosure Condition

FOR YOUR INFORMATION, THE TOTAL CALORIES ARE PROVIDED BELOW FOR EACH SANDWICH.

1

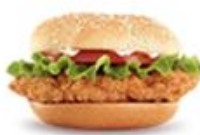

Premium Crispy Chicken Classic

Sandwich

Crispychicken breast filet

Green Lettuce

Slice of Tomato

Mayonnaisedressing
2

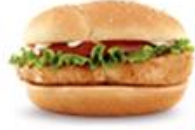

Premium Grilled

Chiden Classic

Sandwich

Grilled chicken breast filet

Green Lettuce

Slice of Tomato

Mayonnaisedressing

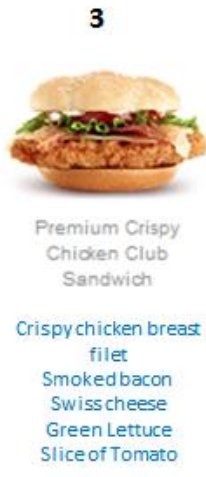

620 calories
4

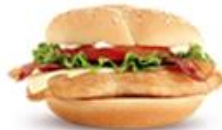

Premium Grilled

Chicken Club

Sandwich

Grilled chicken breast filet Smoked bacon Swiss cheese

Green Lettuce

Slice of Tomato

460 calories
5

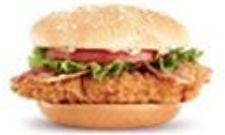

Premium Crispy

Chideen Ranch BLT

Sandwich

Crispychicken breast filet

Smoked bacon

Creamyranch sauce

Green Lettuce

Slice of Tomato

540 calories
6

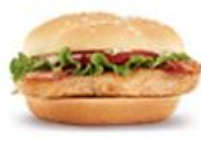

Premium Grilled Chicken Ranch BLT Sandwich

Grilledchicken breast filet

Smoked bacon

Creamy ranch sauce

Green Lettuce

Slice of Tomato

380 calories 
Figure S2a.3: Salient Exercise Equivalent Disclosure Condition

FOR YOUR INFORMATION, THE NUMBER OF MINUTES RUNNING ON A TREADMILL IT TAKES TO BURN THE TOTAL CALORIES ARE PROVIDED BELOW FOR EACH SANDWICH.

\begin{tabular}{|c|c|c|c|c|c|c|}
\hline & 1 & 2 & 3 & 4 & 5 & 6 \\
\hline & $\begin{array}{l}\text { Premium Crispy } \\
\text { Chioken Classic } \\
\text { Sandwich }\end{array}$ & $\begin{array}{l}\text { Premium Grilled } \\
\text { Chiden Classic } \\
\text { Sandwich }\end{array}$ & $\begin{array}{l}\text { Premium Crispy } \\
\text { Chidien Club } \\
\text { Sandwich }\end{array}$ & $\begin{array}{l}\text { Premium Grilled } \\
\text { Chidken Club } \\
\text { Sandwich }\end{array}$ & $\begin{array}{c}\text { Premium Crispy } \\
\text { Chiden Ranch BLT } \\
\text { Sandwich }\end{array}$ & $\begin{array}{l}\text { Premium Grilled } \\
\text { Chiden Ranch BLT } \\
\text { Sandwich }\end{array}$ \\
\hline TOTAL MINUTES & $\begin{array}{l}\text { Crispychicken breast } \\
\text { filet } \\
\text { Green Lettuce } \\
\text { Slice of Tomato } \\
\text { Mayonnaise dressing }\end{array}$ & $\begin{array}{c}\text { Grilled chicken breast } \\
\text { filet } \\
\text { Green Lettuce } \\
\text { Slice of Tomato } \\
\text { Mayonnaise dressing }\end{array}$ & $\begin{array}{c}\text { Crispychicken breast } \\
\text { filet } \\
\text { Smoked bacon } \\
\text { Swisscheese } \\
\text { Green Lettuce } \\
\text { Slice of Tomato }\end{array}$ & $\begin{array}{c}\text { Grilled chicken breast } \\
\text { filet } \\
\text { Smoked bacon } \\
\text { Swiss cheese } \\
\text { Green Lettuce } \\
\text { Slice of Tomato }\end{array}$ & $\begin{array}{c}\text { Crispy chicken breast } \\
\text { filet } \\
\text { Smoked bacon } \\
\text { Creamyranch sauce } \\
\text { Green Lettuce } \\
\text { Slice of Tomato }\end{array}$ & $\begin{array}{c}\text { Grilled chicken breast } \\
\text { filet } \\
\text { Smoked bacon } \\
\text { Creamy ranch sauce } \\
\text { Green Lettuce } \\
\text { Slice of Tomato }\end{array}$ \\
\hline $\begin{array}{r}\text { TOTAL MINUTES } \\
\text { OF RUNNING } \\
\text { REQUIRED TO }\end{array}$ & & & & & & \\
\hline $\begin{array}{r}\text { BURN CALORIES } \\
\text { IN THE } \\
\text { SANDWICH }\end{array}$ & 46 minutes & 32 minutes & 56 minutes & 42 minutes & 49 minutes & 35 minutes \\
\hline
\end{tabular}

Figure S2a.4: Both salient calorie and plus Exercise Equivalent disclosures

FOR YOUR INFORMATION, THE TOTAL CALORIES ARE PROVIDED BELOW EACH CHOICE. IT TAKES ABOUT 30 MINUTES RUNNING ON A TREADMILL TO BURN AN INTAKE OF 330 CALORIES.

1

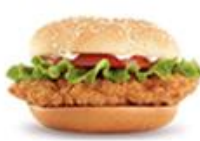

Premium Crispy

Chicken Classic

Sandwich

Crispychicken breast

filet

Green Lettuce

Slice of Tomato

Mayonnaisedressing
2

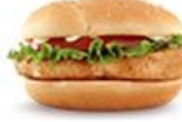

Premium Grilled

Chiden Classic

Sandwich

Grilled chicken breast

$$
\text { filet }
$$

Green Lettuce

Slice of Tomato

Mayonnaise dressing
3

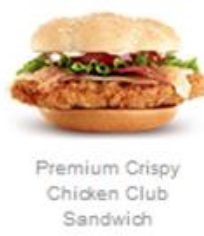

Crispychicken breast

filet

Smoked bacon

Swiss cheese

Green Lettuce

Slice of Tomato

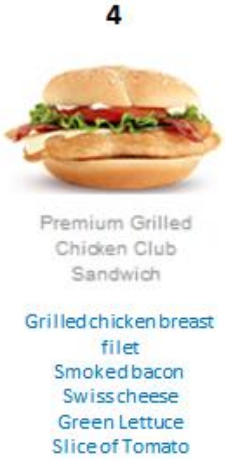

460 calories
5

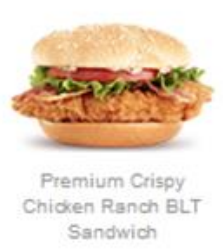

Crispychicken breast

$$
\text { filet }
$$

Smoked bacon

Creamyranch sauce

Green Lettuce

Slice of Tomato

540 calories

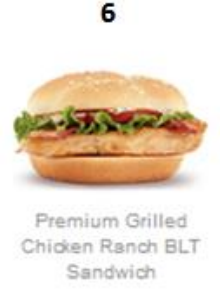

Grilled chicken breast filet Smoked bacon Creamy ranch sauce Green Lettuce

620 calories

460 calories

380 calories 
Figure S2a.5: Mere-Reminder Manipulation 1 - estimate total calories in a personal pan cheese pizza

How many calories do you think there are in a Pizza Hut 6" Personal Pan Cheese Pizza?

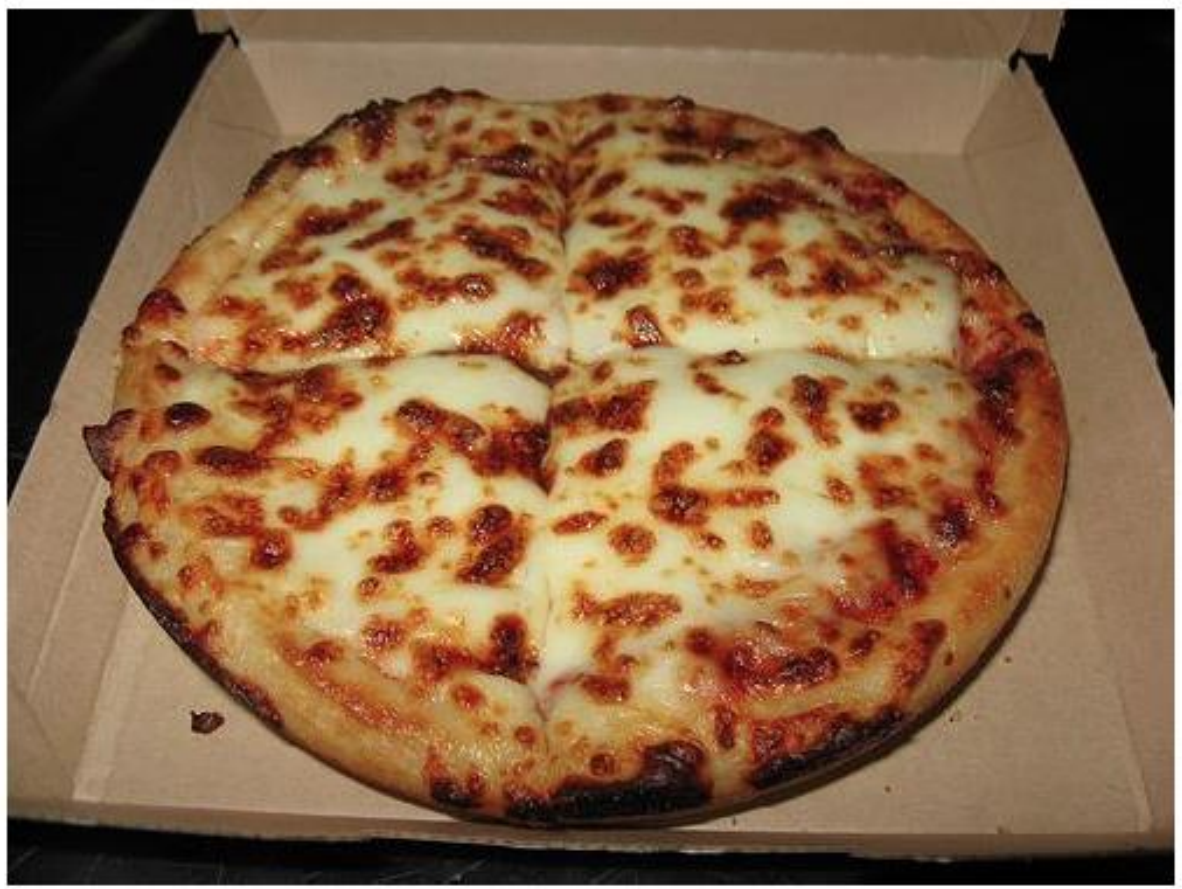

Figure S2a.6: Mere-Reminder Manipulation 2 - estimate total daily calories recommended by USDA

What is your best estimate of how many total calories per day (all meals, snacks and drinks) are recommended for your age, gender and activity level by the USDA dietary guidelines?

Figure S2a.7: Mere-Reminder Manipulation 3 - Estimate minutes required to burn 300 calories running on a treadmill

What is your best estimate of how long it takes to burn 300 calories by running on a treadmill? 
Figure S2a.8: Mere-Reminder Manipulation 3 - Estimate USDA recommended total daily calories for personal age and activity level

Please read the following information carefully.

The recommended total number of calories per day (all meals, snacks and drink) in the USDA dietary guidelines are:

$\begin{array}{lr}\text { Men under 25 years old: } & 2800 \text { calories } \\ \text { Men aged 26-45: } & 2600 \text { calories } \\ \text { Men aged 46-65: } & 2400 \text { calories } \\ \text { Mend aged } 66 \text { and up: } & 2200 \text { calories }\end{array}$

Women under 25 years old: 2200 calories

Women aged 26-50: $\quad 2000$ calories

Women aged 51 and up: 1800 calories

These guidelines are for a person who is the average height for their gender and who has a moderately active lifestyle.

Taller people should consumer more calories and shorter people should consumer fewer calories.

People who are sedentary should consume about $10 \%$ fewer calories and people who are highly physically active should consume about $10 \%$ more.

Based on this, what is your best estimate of how many total calories per day (all meals, snacks and drinks) are recommended for you by the USDA dietary guidelines? 


\section{Study 2b Materials ${ }^{6}$}

Figure S2b.1: Control Condition

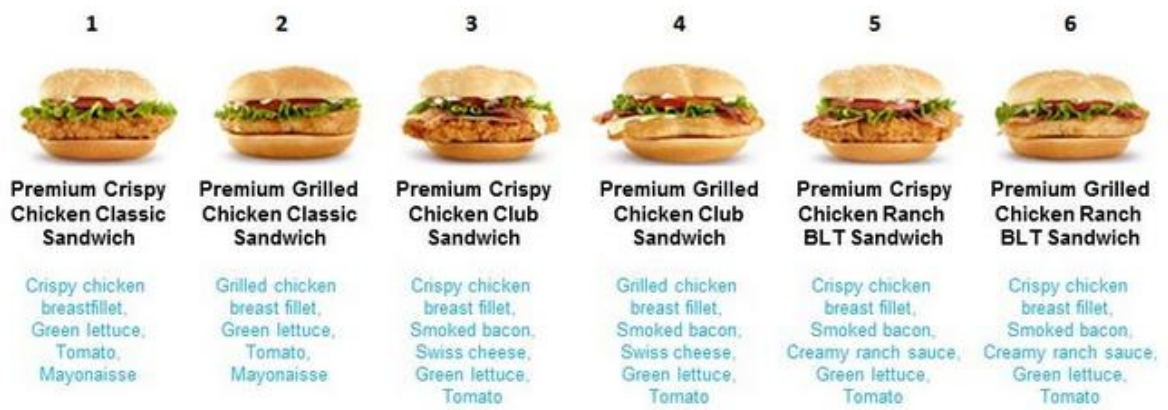

Figure S2b.2: Information Condition
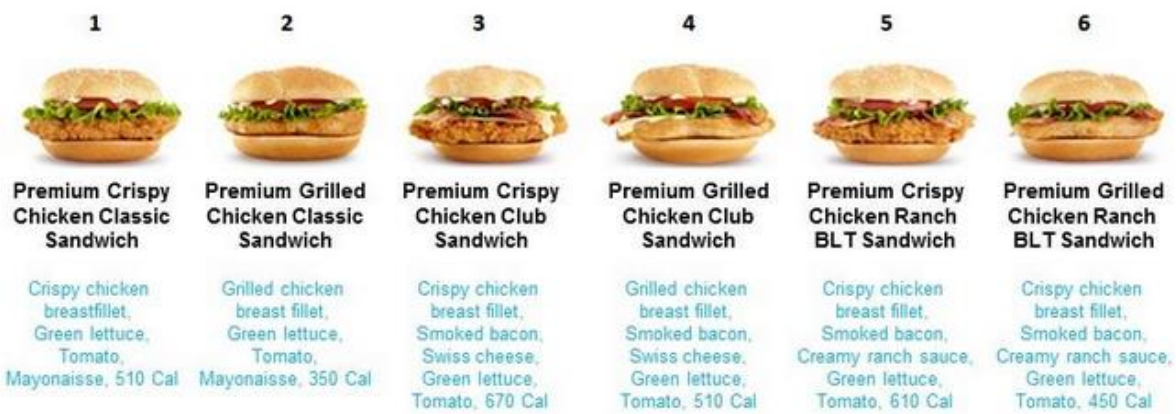

Figure S2b.3: Salient Calorie Disclosure Condition

FOR YOUR INFORMATION, THE TOTAL CALORIES ARE PROVIDED BELOW FOR EACH SANDWICH:

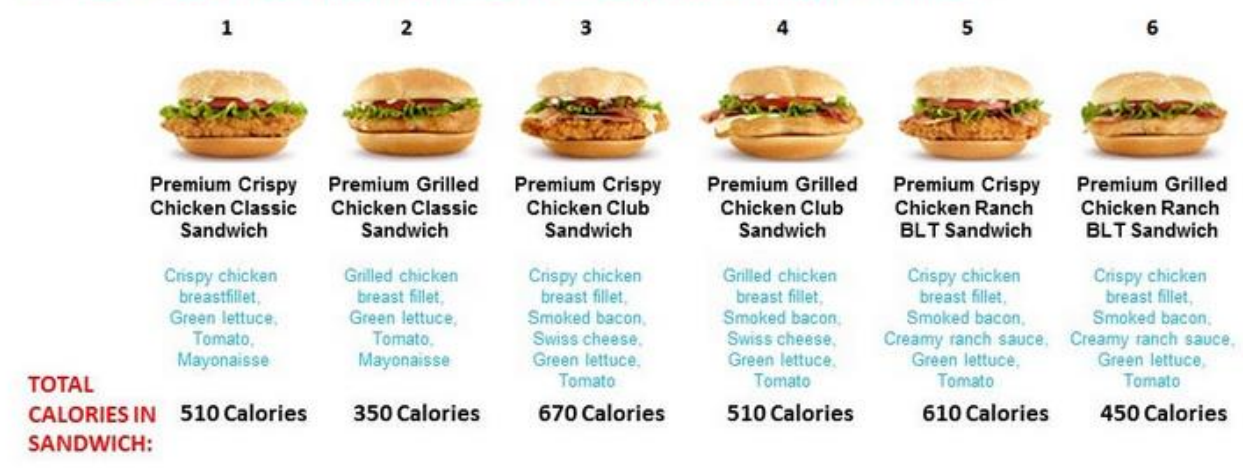

${ }^{6}$ Study $2 b$ and Study $2 c$ used the same stimuli 
Figure S2b.4: Salient Exercise Equivalent Disclosure Condition

FOR YOUR INFORMATION, THE NUMBER OF MINUTES RUNNING ON A TREADMILL IT TAKES TO BURN THE TOTAL CALORIES ARE PROVIDED BELOW FOR EACH SANDWICH

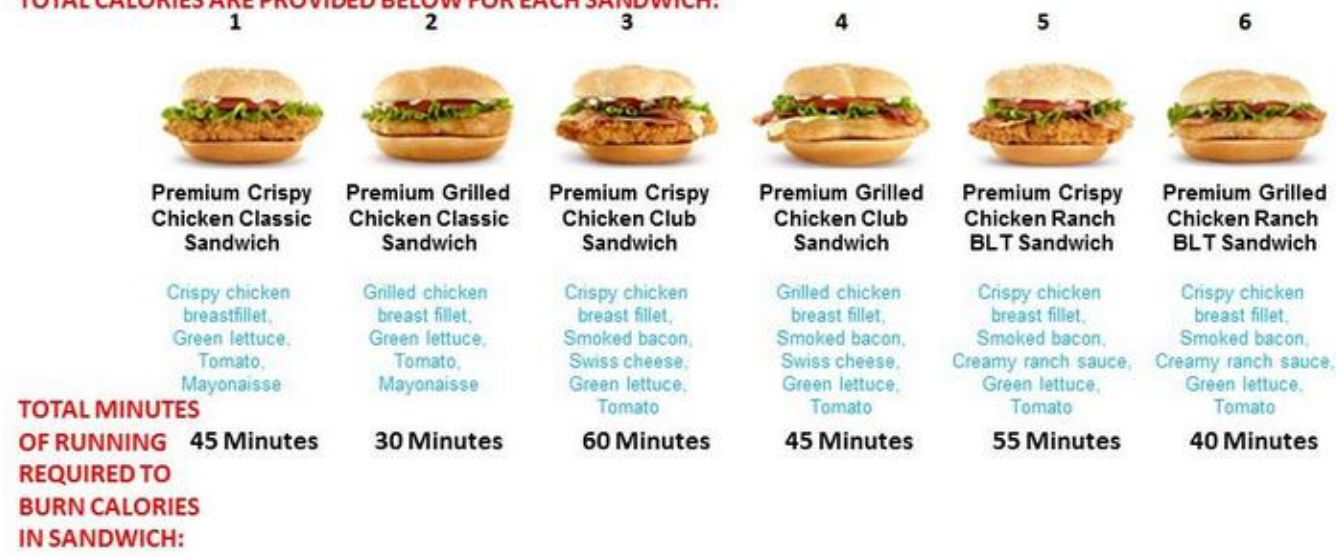

Figure S2b.5: Both salient calorie and plus Exercise Equivalent disclosures

FOR YOUR INFORMATION, THE TOTAL CALORIES ARE PROVIDED BELOW FOR EACH SANDWICH.

ITTAKES ABOUT 3 MINUTES RUNNING ONA TREADMILTO BURNANINTTAKE OF 330 CALORIES,

\begin{tabular}{|c|c|c|c|c|c|c|}
\hline & $\begin{array}{l}\text { Premium Crispy } \\
\text { Chicken Classic } \\
\text { Sandwich }\end{array}$ & $\begin{array}{c}\text { Premium Grilled } \\
\text { Chicken Classic } \\
\text { Sandwich }\end{array}$ & $\begin{array}{l}\text { Premium Crispy } \\
\text { Chicken Club } \\
\text { Sandwich }\end{array}$ & $\begin{array}{l}\text { Premium Grilled } \\
\text { Chicken Club } \\
\text { Sandwich }\end{array}$ & $\begin{array}{l}\text { Premium Crispy } \\
\text { Chicken Ranch } \\
\text { BLT Sandwich }\end{array}$ & $\begin{array}{l}\text { Premium Grilled } \\
\text { Chicken Ranch } \\
\text { BLT Sandwich }\end{array}$ \\
\hline TOTAL & $\begin{array}{c}\text { Crispy chicken } \\
\text { breastillet, } \\
\text { Green lettuce. } \\
\text { Tomato. } \\
\text { Mayonaisse }\end{array}$ & $\begin{array}{c}\text { Grilled chicken } \\
\text { breast fillet, } \\
\text { Green lettuce, } \\
\text { Tomato. } \\
\text { Mayonaisse }\end{array}$ & $\begin{array}{l}\text { Crispy chicken } \\
\text { breast fillet, } \\
\text { Smoked bacon, } \\
\text { Swiss cheese. } \\
\text { Green lettuce. } \\
\text { Tomato }\end{array}$ & $\begin{array}{l}\text { Grilled chicken } \\
\text { breast fillot, } \\
\text { Smoked bacon, } \\
\text { Swiss cheese, } \\
\text { Green lettuce, } \\
\text { Tomate }\end{array}$ & $\begin{array}{c}\text { Crispy chicken } \\
\text { breast fillet. } \\
\text { Smoked bacon. } \\
\text { Creamy ranch sauce, } \\
\text { Green lettuce. } \\
\text { Tomato }\end{array}$ & $\begin{array}{l}\text { Crispy chicken } \\
\text { breast fillet, } \\
\text { Smoked bacon, } \\
\text { Creamy ranch sauce. } \\
\text { Green lettuce. } \\
\text { Tomato }\end{array}$ \\
\hline $\begin{array}{l}\text { CALORIES IN } \\
\text { SANDWICH: }\end{array}$ & 510 Calories & 350 Calories & 670 Calories & 510 Calories & 610 Calories & 450 Calories \\
\hline
\end{tabular}


Figure S2b.6: Mere-Reminder Manipulation 1: Estimate Calories

Please estimate how many calories you think each sandwich has

Please enter your estimates below.

Sandwich 1

Sandwich 2

Sandwich 3

Sandwich 4

Sandwich 5

Sandwich 6

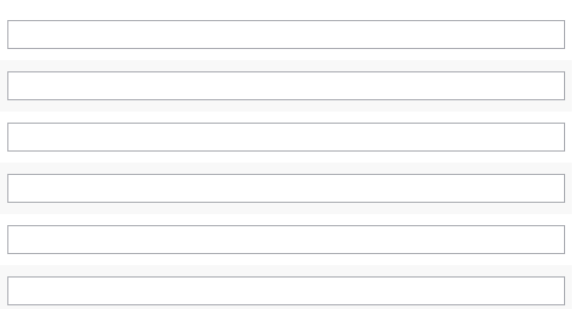

Figure S2b.7: Mere-Reminder Manipulation 2: Estimate Exercise Equivalent

Please estimate how many minutes running on a treadmill you think it would take to burn off the calories in each sandwich.

Please enter your estimates below.

Sandwich 1

Sandwich 2

Sandwich 3

Sandwich 4

Sandwich 5

Sandwich 6 


\section{Study 3 Materials}

Figure S3.1: Four snacks used as food choices.

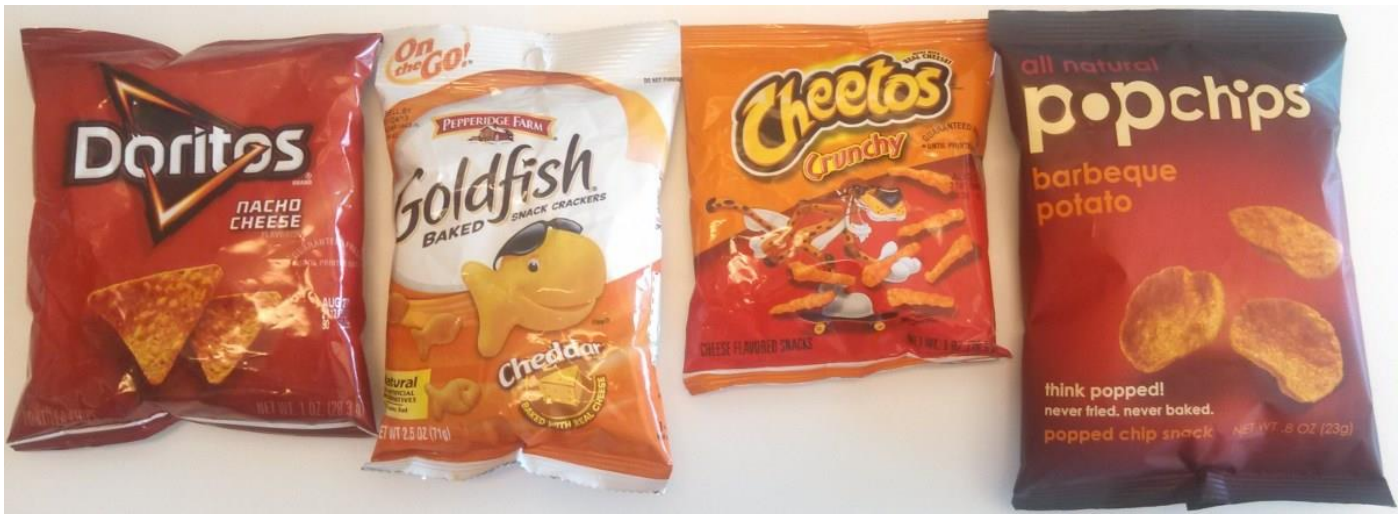

Figure S3.2: Cardboard box with labels used to provide salient calorie disclosures for two of the snacks.

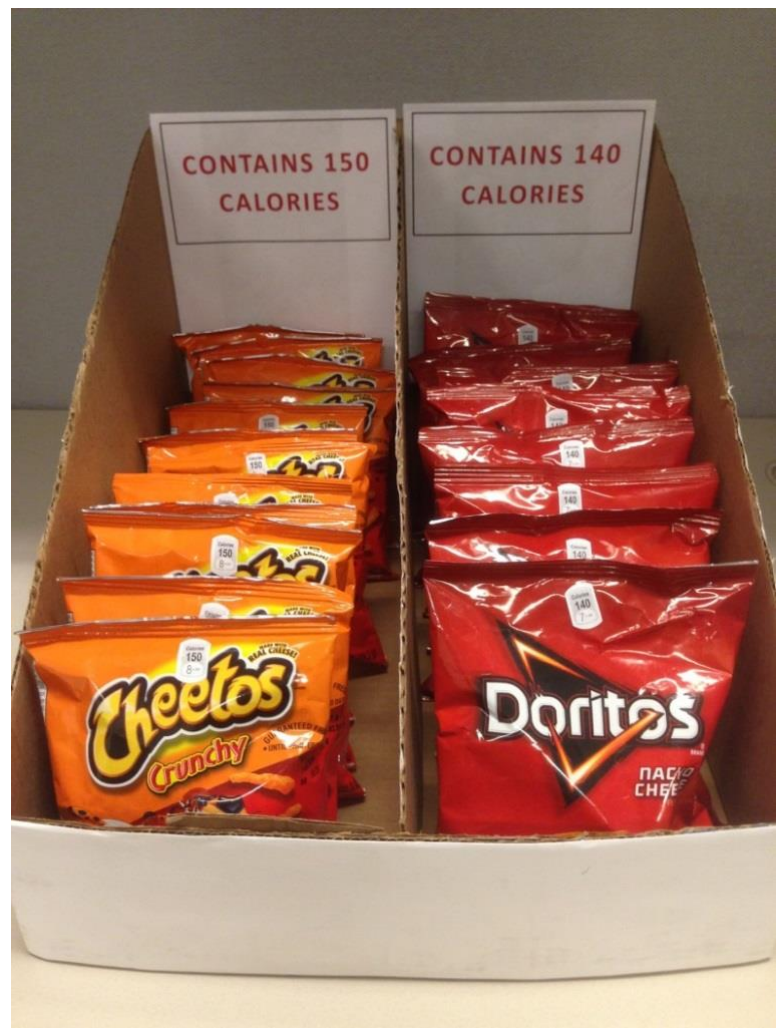

Figure S3.3: Sticker used for industry-format label (actual size).

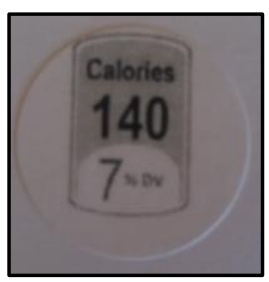


Figure S4.3: Self versus Others Estimation Task designed to test calorie perception of stimuli used. Average answer is participants' estimates of the average answer of other survey takers.

\begin{tabular}{|c|c|c|c|c|}
\hline \# & Questions & Your Answer & Average Answer & Units \\
\hline 1 & How many calories are there in Doritos Nacho Cheese? (see actual product) & & & Calories \\
\hline 2 & How many calories are there in Goldfish Baked Snack Crackers? (see actual product) & & & Calories \\
\hline 3 & How many calories are there in Cheetos Crunchy? (see actual product) & & & Calories \\
\hline 4 & How many calories are there in Popchips Barbeque Potato? (see actual product) & & & Calories \\
\hline 5 & How many calories in total are there in a half cup serving of vanilla ice cream? & & & Calories \\
\hline 6 & How many calories in total are there in a McDonald's Big Mac? & & & Calories \\
\hline 7 & How many calories in total are there in a standard sized Blueberry Muffin at Starbucks? & & & Calories \\
\hline
\end{tabular}

\section{Supplemental Study A Materials}

Figure SA.1: Stimuli used in the control condition of this vignette study. The 4 choice options are undifferentiated in terms of their relative pack sizes.

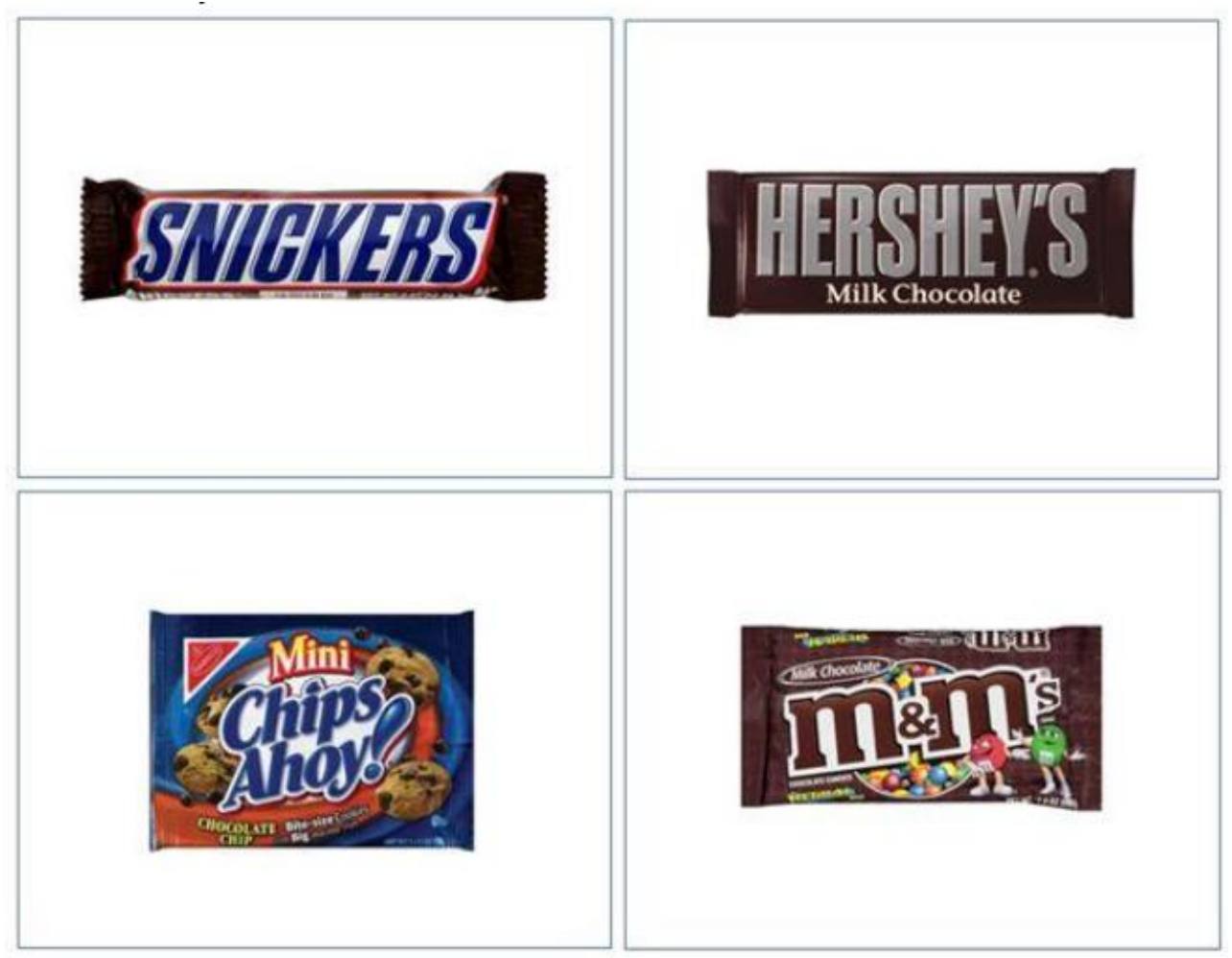


Figure SA.2: Stimuli used in the salient calorie disclosure condition.

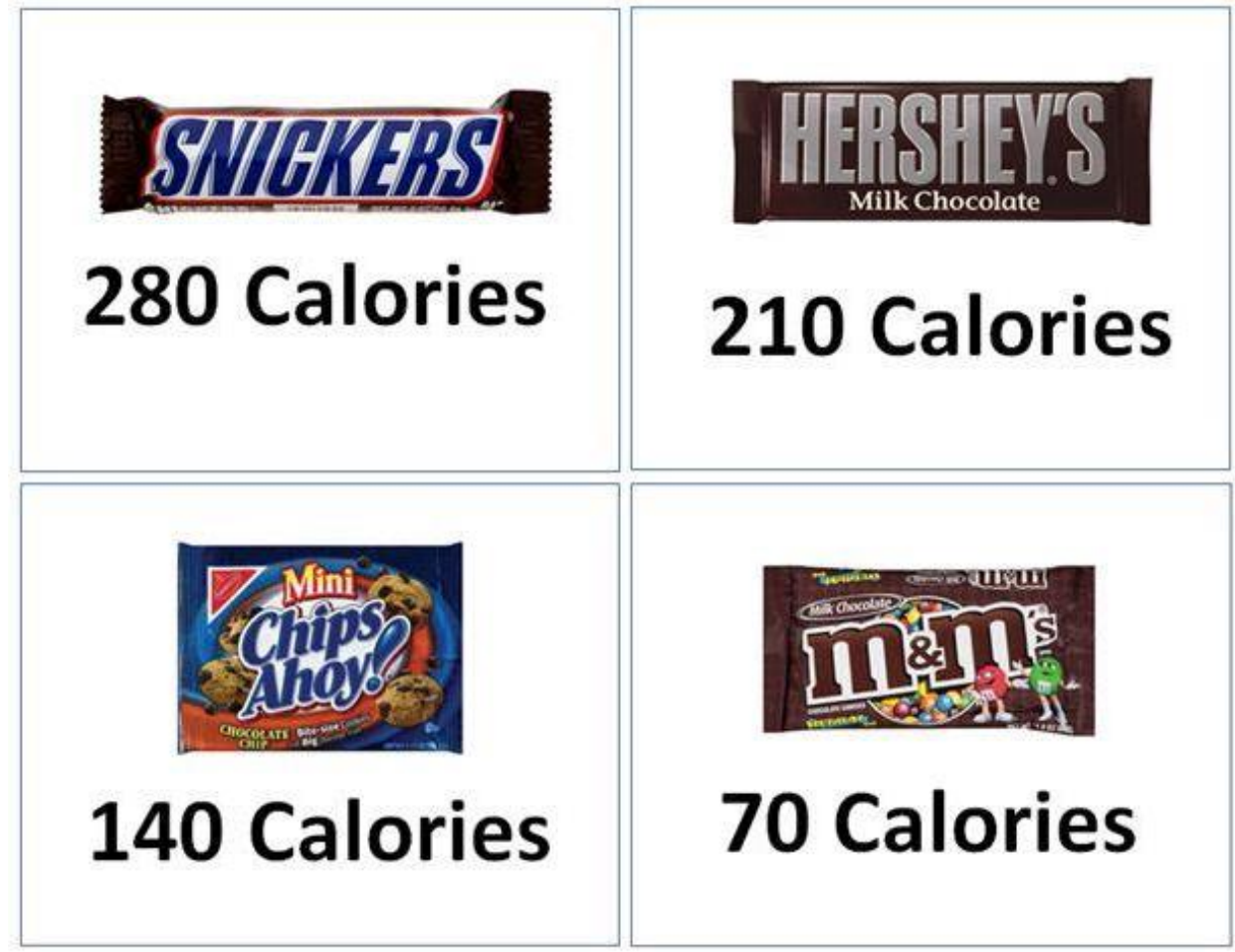

Figure SA.3: Stimuli used in the salient exercise-equivalent (running) disclosure condition.

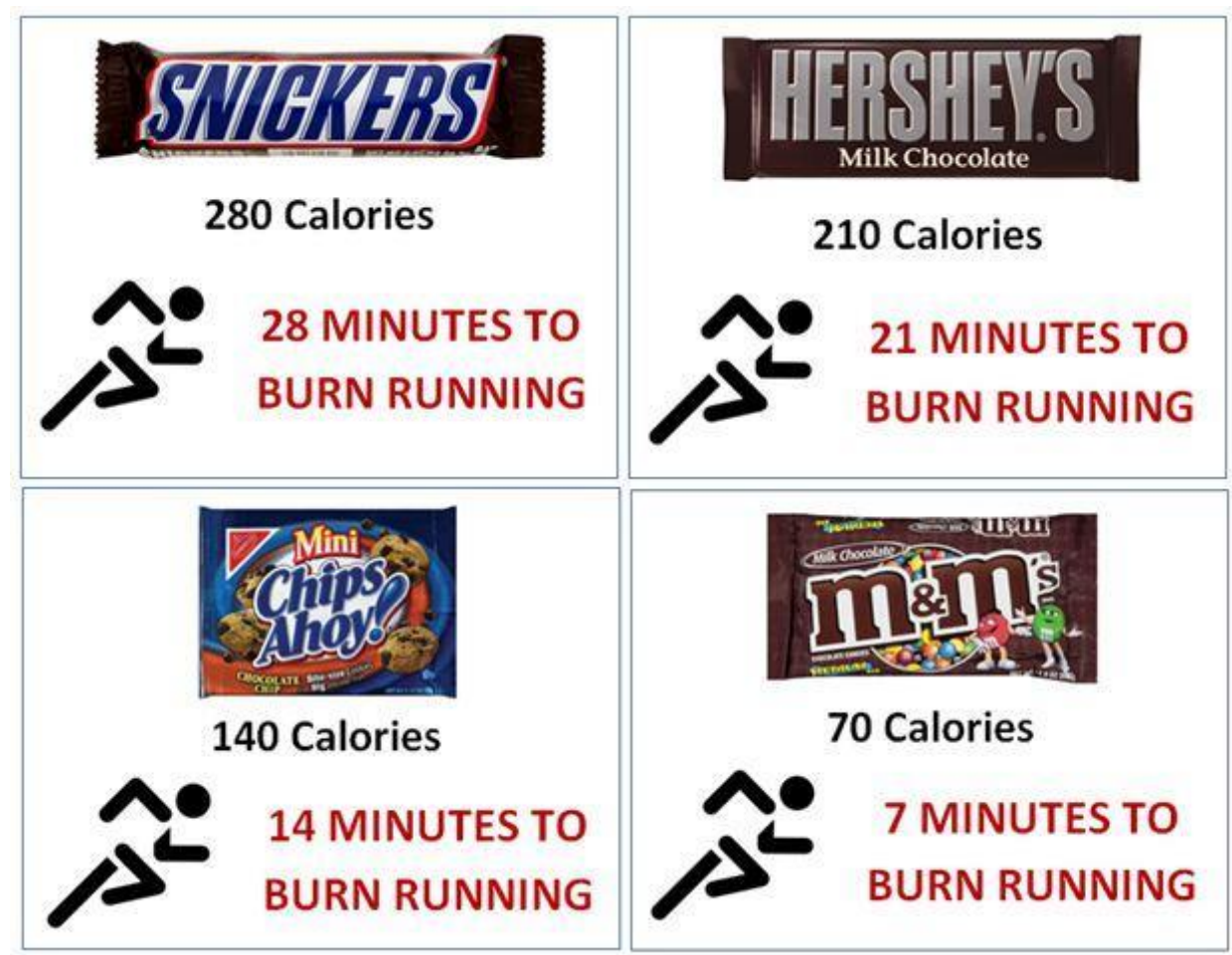


Figure SA.4: Stimuli used in the salient exercise-equivalent (biking) disclosure condition.

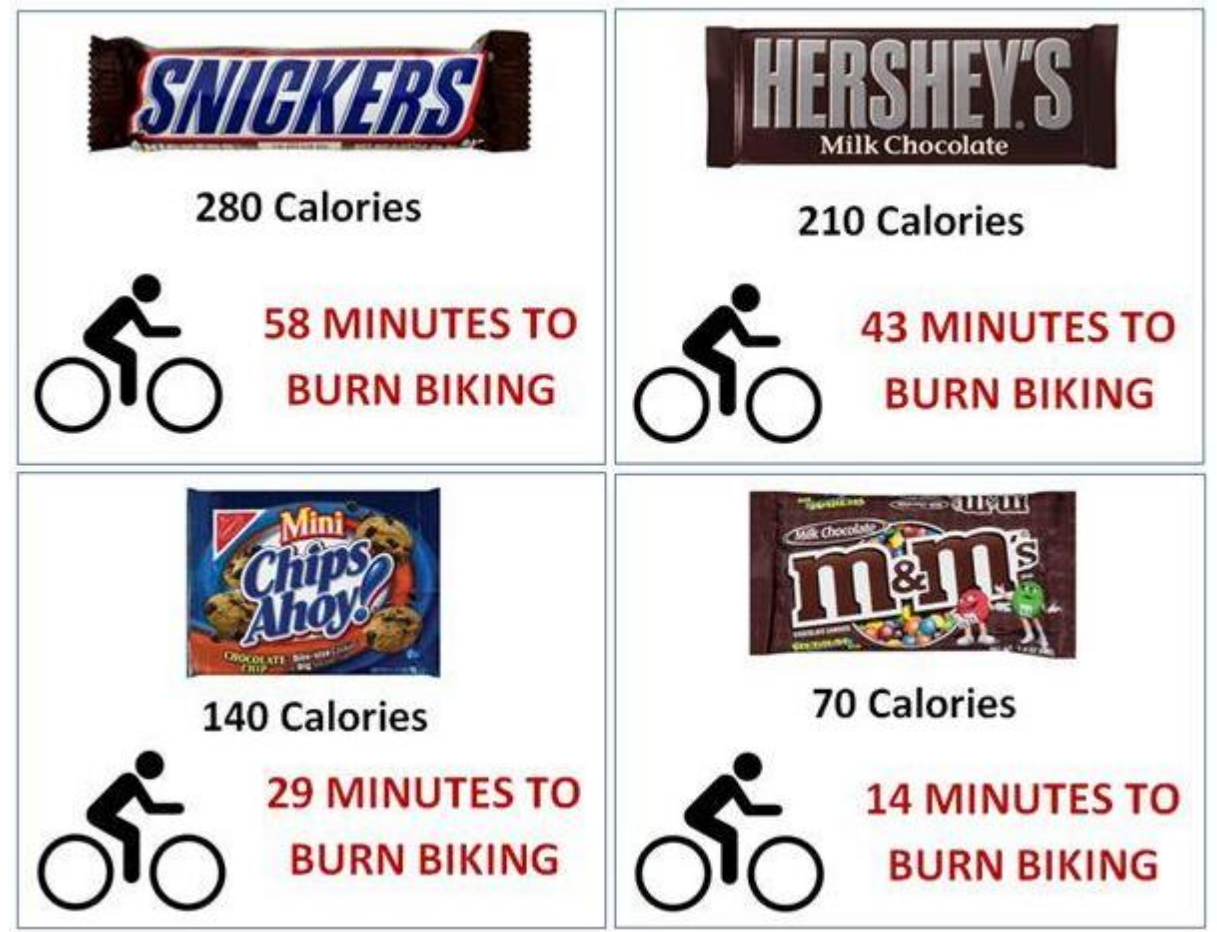

Figure SA.5: Mere-reminder manipulation 1: Estimate calories of focal choice items.

NUMBER OF CALORIES:

Snickers
Chips Ahoy!
Hershey's
M\&M

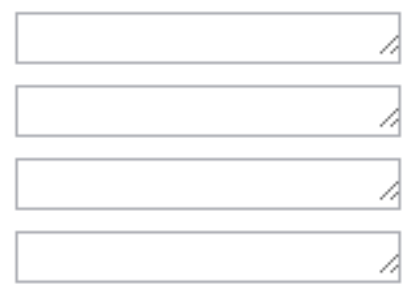


Figure SA.6: Mere-reminder manipulation 2: Estimate minutes of running required to burn calories in focal choice items.

\section{NUMBER OF MINUTES OF RUNNING TO BURN OFF THE CALORIES:}

Snickers
Chips Ahoy!
Hershey's
M\&M

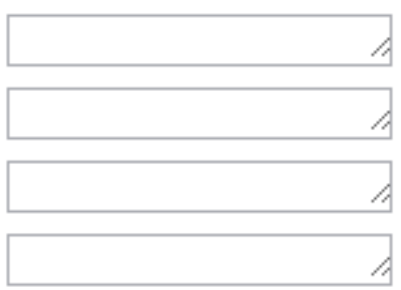

Figure SA.7: Mere-reminder manipulation 3: Estimate minutes of biking required to burn calories in focal choice items.

NUMBER OF MINUTES OF BIKE RIDING TO BURN OFF THE CALORIES:

Snickers
Chips Ahoy!
Hershey's
M\&M

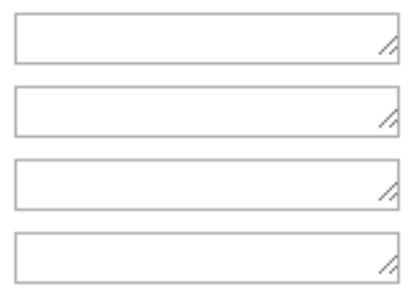

Figure SA.8: Mere-reminder manipulation 4: Estimate minutes of running required to burn 200 calories. How many minutes of running do you think it takes a typical person to burn 200 calories? Please enter your best guess, in minutes.

Figure SA.9: Mere-reminder manipulation 5: Estimate minutes of biking required to burn 200 calories. How many minutes of riding a bike do you think it takes a typical person to burn 200 calories?

Please enter your best guess, in minutes. 


\section{Appendix I. Variable Definitions}

Table 1: Details of regression coefficients in tables S1.2, S2.2-S2.3, and S3.2-S3.4

\section{Regression Coefficients}

Salient intervention

Both interventions

Intervention comparison

\section{Meaning}

1 if either salient disclosures or mere-reminders were present, 0 otherwise

1 if both salient disclosures and mere-reminders were present, 0 otherwise)

-1 if salient information only, +1 if mere-reminder only, 0 otherwise)

Table 2: Details of regression specifications used in tables S1.2 and S3.2-S3.4

\section{Regression}

All Participants

All participants with Time of Day Fixed Effects
Excluding participants with any potential concerns

Excluding participants whose choices were made by / influenced by kids

\section{Meaning}

All participants in the study included in this specification.

The experiments were run during the whole day, and in order to control for the effect of time-of-day on choices, the day was divided into four time-of-days parts:

Before Lunch : 10 am to $12: 30 \mathrm{pm}$

Early Afternoon: $12: 30 \mathrm{pm}$ to $2 \mathrm{pm}$

Late afternoon : $2 \mathrm{pm}$ to $3: 30 \mathrm{pm}$

Early evening: $3: 30 \mathrm{pm}$ to $5 \mathrm{pm}$

This regression specification included a fixed effect for these time-of-days.

Same specification as in column 1 after excluding participations who did not look at the box lid when making their choice (Study 1), mentioned having an allergy to nuts (Study 1), expressed suspicion about the motives of the study, had research-related training e.g. post-doctoral scholar or professor, or whose choices were made by or were influenced by children.

Same specification as in column 1 after only excluding participations whose choices were made by or were influenced by children accompanying adults at the museum. 


\section{Appendix VII. Tables}

Table S1.1: Average calories chosen in each cell in Study 1

Box lid information

Mere Names

Mere Names

Mere Names

Industry-format icon

Industry-format icon

Industry-format icon

Salient Calorie

Salient Calorie

Salient Calorie

Salient Exercise Equivalent (EE)

Salient Exercise Equivalent (EE)

Salient Exercise Equivalent (EE)

$\begin{array}{lccc}\text { Reminder survey } & \text { Cell } & \text { Calories taken }- & \text { Calories taken }- \\ \text { version } & \text { size } & \text { Mean } & \text { SD } \\ \text { Control } & 55 & 158 & 101 \\ \text { Calorie mere-reminder } & 55 & 163 & 99 \\ \text { EE mere-reminder } & 59 & 138 & 91 \\ \text { Control } & 69 & 183 & 87 \\ \text { Calorie mere-reminder } & 67 & 163 & 100 \\ \text { EE mere-reminder } & 69 & 146 & 103 \\ \text { Control } & 74 & 145 & 103 \\ \text { Calorie mere-reminder } & 78 & 134 & 105 \\ \text { EE mere-reminder } & 76 & 120 & 101 \\ \text { Control } & 76 & 144 & 90 \\ \text { Calorie mere-reminder } & 79 & 137 & 93 \\ \text { EE mere-reminder } & 79 & 142 & 96\end{array}$

Table S1.2: Regression tables with robustness checks for Study 1 (DV = Choice of calories). The constant represents calories chosen in control or industry-format information conditions, without mere-reminders.

\begin{tabular}{|c|c|c|c|c|}
\hline & All Participants & $\begin{array}{l}\text { All participants, } \\
\text { with Time of Day } \\
\text { Fixed Effects }\end{array}$ & $\begin{array}{c}\text { Excluding } \\
\text { participants with } \\
\text { any potential } \\
\text { concerns }\end{array}$ & $\begin{array}{c}\text { Excluding } \\
\text { participants whose } \\
\text { choices were made } \\
\text { by / influenced by } \\
\text { kids }\end{array}$ \\
\hline Constant & $171.81(8.76)^{* *}$ & $170.08(10.50)^{* *}$ & $171.52(8.82)^{* *}$ & $171.52(8.83)^{* *}$ \\
\hline Salient intervention & $-23.30(10.11)^{* *}$ & $-23.42(10.10)^{* *}$ & $-24.72(10.23)^{* *}$ & $-25.02(10.21)^{* *}$ \\
\hline $\begin{array}{l}\text { Both interventions } \\
\text { Intervention } \\
\text { comparison }\end{array}$ & $\begin{array}{c}-11.14(9.69) \\
4.18(5.03)\end{array}$ & $\begin{array}{c}-10.84(9.65) \\
3.44(5.07)\end{array}$ & $\begin{array}{c}-9.52(10.02) \\
6.28(5.18)\end{array}$ & $\begin{array}{c}-8.71(9.87) \\
6.49(5.13)\end{array}$ \\
\hline $\mathrm{N}$ & 836 & 836 & 805 & 818 \\
\hline
\end{tabular}


Table S2.1: Average calories chosen in each cell of Studies 2a, 2b and 2c

Box lid information

$\begin{array}{lcc}\text { Cell } & \text { Calories taken }- & \text { Calories taken }- \\ \text { size } & \text { Mean } & \text { SD }\end{array}$

Study $2 \mathrm{a}$

Mere Names

$\begin{array}{llc}57 & 500 & 102 \\ 51 & 470 & 95 \\ 56 & 431 & 90 \\ 48 & 433 & 99 \\ 60 & 478 & 95 \\ 60 & 481 & 91 \\ 64 & 476 & 96 \\ 58 & 479 & 99 \\ 51 & 457 & 98 \\ 55 & 455 & 93\end{array}$

Salient Calorie

Salient Exercise Equivalent (EE)

Both Salient Calorie \& EE

Mere-Reminder 1 - Pizza

Mere-Reminder 2 - Total daily calories

Mere-Reminder 3 - Translating $300 \mathrm{Cal}$ in to EE

Mere-Reminder 4 - Personal USDA recommendation

300 Cal and Salient Calorie

Total daily calories and Salient Calorie

Study $2 b$

Mere Names

$\begin{array}{lcc}67 & 545 & 111 \\ 61 & 507 & 113 \\ 26 & 508 & 125 \\ 23 & 475 & 107 \\ 13 & 481 & 138 \\ 24 & 513 & 85 \\ 16 & 505 & 131 \\ 26 & 525 & 111\end{array}$

Non-Salient Calorie

Salient Calorie

Salient Exercise Equivalent (EE)

Both Salient Calorie \& EE

Mere-Reminder 1 - Calorie

Mere-Reminder 2 - EE

525

111

Study 2c (Appears as Study 2 in the paper)

Mere Names

$\begin{array}{ccc}131 & 547 & 105 \\ 139 & 512 & 118 \\ 48 & 488 & 102 \\ 47 & 480 & 115 \\ 43 & 470 & 112 \\ 67 & 494 & 112 \\ 70 & 502 & 119\end{array}$

Table S2.2: Regression tables of Study 2c i.e., Study 2 in the paper (DV = Choice of calories). The constant represents calories chosen in control or industry-format information conditions, without mere-reminders.

Constant

Salient intervention

Both interventions

Intervention comparison

$\mathrm{N}$

$* * \mathrm{p}<.05 ;$ numbers in parenthesis are pooled standard errors
All Participants

$528.96(6.86) * *$

$-37.93(10.19) * *$

$-21.04(18.78)$

$7.14(7.53)$

545 
Table S2.3: Regression tables of Study 2 merged data (DV = Choice of calories). The constant represents calories chosen in control or industry-format information conditions, without merereminders.

Constant

Salient intervention

Both interventions

Intervention comparison

$\mathrm{N}$

$* * \mathrm{p}<.05 ;$ numbers in parenthesis are pooled standard errors
All Participants $524.75(5.00)^{* *}$ $-46.64(6.29) * *$ $-22.45(11.05) * *$ $12.02(3.80) * *$ 1361

Table S3.1: Average calories chosen in each cell in Study 3

$\begin{array}{llccc}\text { Box lid information } & \text { Reminder survey } & \text { Cell } & \text { Calories taken }- & \text { Calories taken }- \\ & \text { version } & \text { size } & \text { Mean } & 157 \\ \text { Mere Names } & \text { Control } & 49 & 196 & 122 \\ \text { Mere Names } & \text { Calorie reminder } & 46 & 176 & 119 \\ \text { Mere Names } & \text { EE reminder } & 35 & 160 & 118 \\ \text { Industry-format icon } & \text { Control } & 49 & 180 & 102 \\ \text { Industry-format icon } & \text { Calorie reminder } & 50 & 183 & 107 \\ \text { Industry-format icon } & \text { EE reminder } & 50 & 185 & 109 \\ \text { Salient Calorie } & \text { Control } & 69 & 188 & 115 \\ \text { Salient Calorie } & \text { Calorie reminder } & 76 & 202 & 116 \\ \text { Salient Calorie } & \text { EE reminder } & 75 & 182 & 119 \\ \text { Salient Exercise Equivalent (EE) } & \text { Control } & 68 & 182 & 114 \\ \text { Salient Exercise Equivalent (EE) } & \text { Calorie reminder } & 60 & 178 & 118 \\ \text { Salient Exercise Equivalent (EE) } & \text { EE reminder } & 69 & 117\end{array}$

Table S3.2: $\quad$ Logistic regression tables with robustness checks for Study 3 (DV = Choice of 'healthy' items). The constant represents choices in control or industry-format information conditions, without mere-reminders.

\begin{tabular}{|c|c|c|c|c|}
\hline & All Participants & $\begin{array}{l}\text { All participants, } \\
\text { with Time of Day } \\
\text { Fixed Effects }\end{array}$ & $\begin{array}{l}\text { Excluding } \\
\text { participants with } \\
\text { any potential } \\
\text { concerns }\end{array}$ & $\begin{array}{c}\text { Excluding } \\
\text { participants whose } \\
\text { choices were made } \\
\text { by / influenced by } \\
\text { kids }\end{array}$ \\
\hline Constant & $-0.08(0.20)$ & $0.05(0.23)$ & $-0.09(0.22)$ & $-0.05(0.21)$ \\
\hline Salient intervention & $0.48(0.23)^{* *}$ & $0.49(0.23)^{* *}$ & $0.52(0.25)^{* *}$ & $0.50(0.25)^{* *}$ \\
\hline $\begin{array}{l}\text { Both interventions } \\
\text { Intervention } \\
\text { comparison }\end{array}$ & $\begin{array}{c}0.05(0.22) \\
-0.10(0.12)\end{array}$ & $\begin{array}{c}0.05(0.21) \\
-0.11(0.11)\end{array}$ & $\begin{array}{c}0.07(0.22) \\
-0.11(0.12)\end{array}$ & $\begin{array}{c}0.04(0.22) \\
-0.09(0.12)\end{array}$ \\
\hline 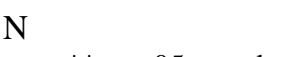 & 696 & 696 & 627 & 637 \\
\hline
\end{tabular}


Table S3.3: Logistic regression tables with robustness checks for Study 3 (DV = Choice of Goldfish). The constant represents choices in control or industry-format information conditions, without mere-reminders.

\begin{tabular}{|c|c|c|c|c|}
\hline & All Participants & $\begin{array}{c}\text { All participants with } \\
\text { Time of Day Fixed } \\
\text { Effects }\end{array}$ & $\begin{array}{l}\text { Excluding } \\
\text { participants with } \\
\text { any potential } \\
\text { concerns }\end{array}$ & $\begin{array}{c}\text { Excluding } \\
\text { participants whose } \\
\text { choices were made } \\
\text { by / influenced by } \\
\text { kids }\end{array}$ \\
\hline Constant & $-1.29(0.25)^{* *}$ & $-1.23(0.27)^{* *}$ & $-1.37(0.27)^{* *}$ & $-1.33(0.27)^{* *}$ \\
\hline Salient intervention & $0.43(0.27)$ & $0.44(0.27)$ & $0.56(0.31)^{*}$ & $0.49(0.29)^{*}$ \\
\hline Both interventions & $0.10(0.22)$ & $0.11(0.23)$ & $-0.02(0.23)$ & $-0.01(0.23)$ \\
\hline $\begin{array}{l}\text { Intervention } \\
\text { comparison }\end{array}$ & $-0.01(0.12)$ & $-0.02(0.13)$ & $-0.06(0.13)$ & $-0.07(0.13)$ \\
\hline $\mathrm{N}$ & 696 & 696 & 627 & 637 \\
\hline
\end{tabular}

Table S3.4: Regression tables with robustness checks for Study 3 (DV = Choice of calories). The constant represents calories chosen in control or industry-format information conditions, without mere-reminders..

\begin{tabular}{|c|c|c|c|c|}
\hline Constant & All Participants & $\begin{array}{l}\text { All participants, } \\
\text { with Time of Day } \\
\text { Fixed Effects }\end{array}$ & $\begin{array}{l}\text { Excluding } \\
\text { participants with } \\
\text { any potential } \\
\text { concerns }\end{array}$ & $\begin{array}{c}\text { Excluding } \\
\text { participants whose } \\
\text { choices were made } \\
\text { by / influenced by } \\
\text { kids } \\
154.53(12.50)^{* *}\end{array}$ \\
\hline Salient intervention & $25.06(13.26)^{*}$ & $24.74(13.28)^{*}$ & $32.93(14.43)^{* *}$ & $29.54(14.25)^{* *}$ \\
\hline $\begin{array}{l}\text { Both interventions } \\
\text { Intervention } \\
\text { comparison }\end{array}$ & $\begin{array}{c}4.60(11.94) \\
0.41(6.48)\end{array}$ & $\begin{array}{c}4.93(11.92) \\
0.50(6.51)\end{array}$ & $\begin{array}{c}-2.19(12.59) \\
-2.33(6.91)\end{array}$ & $\begin{array}{c}-0.33(12.49) \\
-2.66(6.83)\end{array}$ \\
\hline 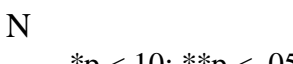 & 696 & 696 & 627 & 637 \\
\hline
\end{tabular}




\section{Appendix VIII. Supplemental Analysis and Moderators}

Table 1: Comparing Salient Calories vs. Salient Exercise Equivalents

Average calories taken with salient calorie disclosures and exercise equivalent disclosures of comparable salience. The SDs are shown in parenthesis. The results suggest that consumer's inability to reason with calories is not a substantial factor in non-effectiveness of calorie disclosures.

$\begin{array}{rccc}\text { No disclosure } & \begin{array}{c}\text { Salient calorie } \\ \text { disclosure }\end{array} & \begin{array}{c}\text { Salient exercise } \\ \text { equivalent disclosure }\end{array} & \begin{array}{c}\text { t-test (column 2 vs. } \\ \text { column 3) }\end{array} \\ 153(97) & 133(103) & 141(93) & t(460)<1 \\ 536(107) & 485(104) & 457(105) & t(249)=2.19, p=.04 \\ & & & \\ 176(120) & 192(116) & 181(116) & t(415)<1\end{array}$

Tables 2: Examining Moderators in Study 1

Table 2a: Moderation by Overweight Indicator

\begin{tabular}{lcccc} 
Source & $\beta$ & $\mathrm{SE}$ & $\mathrm{t}$ & $\mathrm{p}$ \\
\hline Constant & 161.02 & 14.61 & 11.024 & $<.0001$ \\
Salient Intervention (Disclosure or Mere-Reminder) & -16.40 & 15.54 & -1.055 & 0.292 \\
Overweight (BMI $>$ 25) & 20.10 & 18.80 & 1.069 & 0.285 \\
Salient Intervention $x$ Overweight & -28.42 & 20.33 & -1.398 & 0.163 \\
\hline
\end{tabular}

Baseline: $\mathrm{BMI}<=25$

Table 2b: Moderation by Gender Indicator

\begin{tabular}{lcccc} 
Source & $\beta$ & $\mathrm{SE}$ & $\mathrm{t}$ & $\mathrm{p}$ \\
\hline Constant & 169.75 & 12.44 & 13.63 & $<.0001$ \\
Salient Intervention (Disclosure or Mere-Reminder) & -27.08 & 13.44 & -2.01 & 0.04 \\
Male & 7.24 & 17.67 & 0.41 & 0.68 \\
Salient Intervention x Male & -6.21 & 19.19 & -0.32 & 0.74 \\
\hline
\end{tabular}

Baseline: Female 
Table 2c: Moderation by Ethnicity Indicator

\begin{tabular}{lcccc} 
Source & $\beta$ & $\mathrm{SE}$ & $\mathrm{t}$ & $\mathrm{p}$ \\
\hline Constant & 206.80 & 19.29 & 10.71 & $<.0001$ \\
Salient Intervention (Disclosure or Mere-Reminder) & -44.90 & 20.81 & -2.15 & 0.03 \\
White & -39.62 & 21.71 & -1.82 & 0.06 \\
Salient Intervention x White & 15.67 & 23.45 & 0.66 & 0.50 \\
\hline
\end{tabular}

Baseline: Non-white

Table 2d: Moderation by Income Category

\begin{tabular}{lcccc} 
Source & $\beta$ & $\mathrm{SE}$ & $\mathrm{t}$ & $\mathrm{p}$ \\
\hline Constant & 159.25 & 21.69 & 7.34 & $<.0001$ \\
Salient Intervention (Disclosure or Mere-Reminder) & -10.67 & 23.29 & -0.45 & 0.64 \\
$\$ 30,000$ to 50,000 & 21.06 & 32.53 & 0.64 & 0.51 \\
$\$ 50,000$ to 80,000 & -1.95 & 29.36 & -0.06 & 0.94 \\
$\$ 80,000$ to 130,000 & 18.56 & 27.64 & 0.67 & 0.50 \\
Above $\$ 130,000$ & 31.30 & 28.61 & 1.09 & 0.27 \\
Salient Intervention x \$30,000 to 50,000 & -13.32 & 34.96 & -0.38 & 0.70 \\
Salient Intervention x \$50,000 to 80,000 & -7.03 & 31.62 & -0.22 & 0.82 \\
Salient Intervention x \$80,000 to 130,000 & -33.53 & 29.98 & -1.11 & 0.26 \\
Salient Intervention x Above \$130,000 & -38.91 & 30.96 & -1.25 & 0.20 \\
\hline Baseline: Below $\$ 30,000$ & & & &
\end{tabular}

Baseline: Below $\$ 30,000$

Table 2e: Moderation by Age Category

\begin{tabular}{lcccc} 
Source & $\beta$ & $\mathrm{SE}$ & $\mathrm{t}$ & $\mathrm{p}$ \\
\hline Constant & 184.34 & 19.97 & 9.22 & $<.0001$ \\
Salient Intervention (Disclosure or Mere-Reminder) & -18.11 & 21.45 & -0.84 & 0.39 \\
25-34 years & -32.42 & 25.18 & -1.28 & 0.19 \\
35-44 years & 29.59 & 29.69 & 0.99 & 0.31 \\
45-60 years & 0.13 & 26.74 & 0.00 & 0.99 \\
60 years or older & -69.84 & 36.28 & -1.92 & 0.05 \\
Salient Intervention x 25-34 years & -6.18 & 27.18 & -0.22 & 0.82 \\
Salient Intervention x 35-44 years & -50.13 & 31.68 & -1.58 & 0.11 \\
Salient Intervention x 45-60 years & -20.35 & 29.22 & -0.69 & 0.48 \\
Salient Intervention x 60 years or older & 18.40 & 39.61 & 0.46 & 0.64 \\
\hline
\end{tabular}

Baseline: Below 25 years 
Table 2f: Moderation by Years in School Category

\begin{tabular}{lcccc} 
Source & $\beta$ & $\mathrm{SE}$ & $\mathrm{t}$ & $\mathrm{p}$ \\
\hline Constant & 211.67 & 24.91 & 8.49 & $<.0001$ \\
Salient Intervention (Disclosure or Mere-Reminder) & -37.08 & 27.80 & -1.33 & 0.18 \\
1-3 years College & -25.83 & 31.75 & -0.81 & 0.41 \\
4 years College & -48.67 & 30.51 & -1.59 & 0.11 \\
Graduate & -60.42 & 28.84 & -2.09 & 0.03 \\
PhD & 12.71 & 42.23 & 0.30 & 0.76 \\
Salient Intervention x 1-3 years College & -1.07 & 35.07 & -0.03 & 0.97 \\
Salient Intervention x 4 years College & 18.46 & 33.53 & 0.55 & 0.58 \\
Salient Intervention x Graduate & 16.17 & 32.06 & 0.50 & 0.61 \\
Salient Intervention x PhD & -52.16 & 46.77 & -1.11 & 0.26 \\
\hline
\end{tabular}

Baseline: High School or Less

Tables 3: Examining Moderators in Study 2 (merged data)

Table 3a: Moderation by Overweight Indicator

\begin{tabular}{lcccc} 
Source & $\beta$ & $\mathrm{SE}$ & $\mathrm{t}$ & $\mathrm{p}$ \\
\hline Constant & 523.56 & 7.83 & 66.86 & $<.0001$ \\
Salient Intervention (Disclosure or Mere-Reminder) & -20.92 & 11.29 & -1.85 & 0.06 \\
Overweight (BMI $>$ 25) & 9.81 & 11.33 & 0.87 & 0.39 \\
Salient Intervention $x$ Overweight & -27.41 & 15.98 & -1.72 & 0.09 \\
\hline
\end{tabular}

Baseline: $\mathrm{BMI}<=25$

Table 3b: Moderation by Any Weight Loss Goal Indicator

\begin{tabular}{lcccc} 
Source & $\beta$ & $\mathrm{SE}$ & $\mathrm{t}$ & $\mathrm{p}$ \\
\hline Constant & 512.64 & 8.05 & 63.66 & $<.0001$ \\
Salient Intervention (Disclosure or Mere-Reminder) & -59.45 & 9.87 & -6.02 & $<.0001$ \\
Weight Loss Goal & 19.60 & 10.25 & 1.91 & 0.06 \\
Salient Intervention x Weight Loss Goal & 18.68 & 12.56 & 1.49 & 0.14 \\
\hline
\end{tabular}

Baseline: No Weight Loss Goal 
Table 3c: Moderation by Weight Loss Goal Amount

\begin{tabular}{lcccc} 
Source & $\beta$ & $\mathrm{SE}$ & $\mathrm{t}$ & $\mathrm{p}$ \\
\hline Constant & 523.69 & 7.07 & 74.06 & $<.0001$ \\
Salient Intervention (Disclosure or Mere-Reminder) & -49.50 & 9.28 & -5.34 & $<.0001$ \\
Weight Loss Goal Amount & 0.21 & 0.24 & 0.88 & 0.38 \\
Salient Intervention x Weight Loss Goal Amount & -0.47 & 0.28 & -1.68 & 0.09 \\
\hline
\end{tabular}

Table 3d: Moderation by Gender Indicator

\begin{tabular}{lcccc} 
Source & $\beta$ & $\mathrm{SE}$ & $\mathrm{t}$ & $\mathrm{p}$ \\
\hline Constant & 508.71 & 6.65 & 76.52 & $<.0001$ \\
Salient Intervention (Disclosure or Mere-Reminder) & -47.37 & 8.30 & -5.71 & $<.0001$ \\
Male & 36.49 & 10.03 & 3.64 & $<.001$ \\
Salient Intervention x Male & -5.46 & 12.26 & -0.45 & 0.66 \\
\hline
\end{tabular}

Baseline: Female

Table 3e: Moderation by Age

\begin{tabular}{lcccc} 
Source & $\beta$ & $\mathrm{SE}$ & $\mathrm{t}$ & $\mathrm{p}$ \\
\hline Constant & 595.42 & 15.49 & 38.42 & $<.0001$ \\
Salient Intervention (Disclosure or Mere-Reminder) & -56.69 & 18.94 & -2.99 & 0.003 \\
Age & -2.03 & 0.42 & -4.81 & $<.0001$ \\
Salient Intervention x Age & 0.15 & 0.52 & 0.29 & 0.77 \\
\hline
\end{tabular}

Table 3f: Moderation by Activity Level in a Typical Day Indicator

\begin{tabular}{lcccc} 
Source & $\beta$ & $\mathrm{SE}$ & $\mathrm{t}$ & $\mathrm{p}$ \\
\hline Constant & 546.99 & 9.17 & 59.64 & $<.0001$ \\
Salient Intervention (Disclosure or Mere-Reminder) & -59.66 & 11.30 & -5.28 & $<.0001$ \\
Moderately Active or Active & -31.72 & 10.95 & -2.90 & 0.004 \\
Salient Intervention x Moderately Active or Active & 16.74 & 13.47 & 1.24 & 0.21 \\
\hline
\end{tabular}

Baseline: Sedentary 
Table 3g: Moderation by Time Spent Taking the Survey

\begin{tabular}{lcccc} 
Source & $\beta$ & $\mathrm{SE}$ & $\mathrm{t}$ & $\mathrm{p}$ \\
\hline Constant & 544.17 & 22.26 & 24.44 & $<.001$ \\
Salient Intervention (Disclosure or Mere-Reminder) & -68.90 & 31.34 & -2.20 & 0.03 \\
Log time & -8.51 & 11.89 & -0.72 & 0.47 \\
Log Time x Salient Intervention & 16.30 & 16.89 & 0.97 & 0.34 \\
\hline
\end{tabular}

Tables 4: Examining Moderators in Study 3

Table 4a: Moderation by Overweight Indicator

\begin{tabular}{lcccc} 
Source & $\beta$ & $\mathrm{SE}$ & $\mathrm{t}$ & $\mathrm{p}$ \\
\hline Constant & 151.11 & 17.12 & 8.83 & $<.0001$ \\
Salient Intervention (Disclosure or Mere-Reminder) & 34.83 & 18.53 & 1.88 & 0.06 \\
Overweight (BMI $>$ 25) & 18.42 & 24.49 & 0.75 & 0.45 \\
Salient Intervention x Overweight & -16.16 & 26.43 & -0.61 & 0.54 \\
\hline
\end{tabular}

Baseline: $\mathrm{BMI}<=25$

Table 4b: Moderation by Active Health Goal Indicator

\begin{tabular}{lcccc} 
Source & $\beta$ & $\mathrm{SE}$ & $\mathrm{t}$ & $\mathrm{p}$ \\
\hline Constant & 166.67 & 18.33 & 9.09 & $<.0001$ \\
Salient Intervention (Disclosure or Mere-Reminder) & 23.05 & 19.75 & 1.17 & 0.24 \\
Active Health Goal & -13.11 & 23.62 & -0.56 & 0.58 \\
Salient Intervention x Active Health Goal & 6.58 & 25.47 & 0.26 & 0.80 \\
\hline
\end{tabular}

Baseline: No Active Health Goal

Table 4c: Moderation by Gender Indicator

\begin{tabular}{lcccc} 
Source & $\beta$ & $\mathrm{SE}$ & $\mathrm{t}$ & $\mathrm{p}$ \\
\hline Constant & 176.27 & 15.99 & 11.02 & $<.0001$ \\
Salient Intervention (Disclosure or Mere-Reminder) & 15.61 & 17.17 & 0.91 & 0.36 \\
Male & -36.49 & 23.23 & -1.57 & 0.12 \\
Salient Intervention x Male & 23.22 & 25.14 & 0.92 & 0.36 \\
\hline
\end{tabular}

Baseline: Female 
Table 4d: Moderation by Ethnicity Indicator

\begin{tabular}{lcccc} 
Source & $\beta$ & $\mathrm{SE}$ & $\mathrm{t}$ & $\mathrm{p}$ \\
\hline Constant & 146.09 & 23.82 & 6.13 & $<.0001$ \\
Salient Intervention (Disclosure or Mere-Reminder) & 36.26 & 25.81 & 1.41 & 0.16 \\
White & 14.61 & 27.36 & 0.53 & 0.59 \\
Salient Intervention $\mathrm{x}$ White & -8.52 & 29.62 & -0.29 & 0.77 \\
\hline
\end{tabular}

Baseline: Non-white

Table 4e: Moderation by Income Category

\begin{tabular}{lcccc} 
Source & $\beta$ & $\mathrm{SE}$ & $\mathrm{t}$ & $\mathrm{p}$ \\
\hline Constant & 210.00 & 32.89 & 6.39 & $<.0001$ \\
Salient Intervention (Disclosure or Mere-Reminder) & -2.96 & 34.85 & -0.09 & 0.93 \\
$\$ 30,000$ to 50,000 & -103.00 & 48.79 & -2.11 & 0.04 \\
$\$ 50,000$ to 80,000 & -53.53 & 42.96 & -1.25 & 0.21 \\
$\$ 80,000$ to 130,000 & -27.73 & 40.89 & -0.68 & 0.50 \\
Above \$130,000 & -72.65 & 38.26 & -1.90 & 0.06 \\
Salient Intervention x \$30,000 to 50,000 & 83.29 & 51.39 & 1.62 & 0.11 \\
Salient Intervention x \$50,000 to 80,000 & 27.74 & 45.86 & 0.61 & 0.55 \\
Salient Intervention x \$80,000 to 130,000 & 0.62 & 43.47 & 0.01 & 0.99 \\
Salient Intervention x Above \$130,000 & 49.36 & 41.38 & 1.19 & 0.23 \\
\hline Baseline: Below \$30,000
\end{tabular}

Baseline: Below $\$ 30,000$

Table 4f: Moderation by Age Category

\begin{tabular}{lcccc} 
Source & $\beta$ & $\mathrm{SE}$ & $\mathrm{t}$ & $\mathrm{p}$ \\
\hline Constant & 191.00 & 36.32 & 5.26 & $<.0001$ \\
Salient Intervention (Disclosure or Mere-Reminder) & -8.40 & 37.54 & -0.22 & 0.82 \\
25-34 years & -50.36 & 41.77 & -1.21 & 0.23 \\
35-44 years & -21.42 & 43.23 & -0.50 & 0.62 \\
45-60 years & -27.96 & 43.51 & -0.64 & 0.52 \\
60 years or older & -43.22 & 52.77 & -0.82 & 0.41 \\
Salient Intervention x 25-34 years & 63.34 & 43.77 & 1.45 & 0.15 \\
Salient Intervention x 35-44 years & 33.29 & 45.66 & 0.73 & 0.47 \\
Salient Intervention x 45-60 years & 22.22 & 45.77 & 0.49 & 0.63 \\
Salient Intervention x 60 years or older & 45.50 & 56.41 & 0.81 & 0.42 \\
\hline
\end{tabular}

Baseline: Below 25 years 
Table 4g: Moderation by Years in School Category

\begin{tabular}{lcccc} 
Source & $\beta$ & $\mathrm{SE}$ & $\mathrm{t}$ & $\mathrm{p}$ \\
\hline Constant & 136.00 & 51.09 & 2.66 & 0.007 \\
Salient Intervention (Disclosure or Mere-Reminder) & 57.08 & 53.02 & 1.08 & 0.28 \\
1-3 years College & 35.82 & 61.62 & 0.58 & 0.56 \\
4 years College & 6.90 & 55.06 & 0.13 & 0.90 \\
Graduate & 37.85 & 54.27 & 0.70 & 0.49 \\
PhD & -62.25 & 65.13 & -0.96 & 0.34 \\
Salient Intervention x 1-3 years College & -35.06 & 64.14 & -0.55 & 0.58 \\
Salient Intervention x 4 years College & -16.53 & 57.41 & -0.29 & 0.77 \\
Salient Intervention x Graduate & -45.50 & 56.73 & -0.80 & 0.42 \\
Salient Intervention x PhD & 41.28 & 71.62 & 0.58 & 0.56 \\
\hline
\end{tabular}

Baseline: High School or Less 